\title{
Agrobacterium tumefaciens Gene Transfer: How a Plant Pathogen Hacks the Nuclei of Plant and Nonplant Organisms
}

\author{
Salim Bourras, Thierry Rouxel, and Michel Meyer
}

First, second, and third authors: INRA, UMR 1290 INRA-AgroParisTech BIOGER, Avenue Lucien Brétignières, BP 01, F-78850 ThivervalGrignon, France.

Current address of first author: University of Zurich, Institute of Plant Biology, Zollikerstrasse 107, CH-8008 Zürich, Switzerland. Accepted for publication 29 June 2015.

\begin{abstract}
Bourras, S., Rouxel, T., and Meyer, M. 2015. Agrobacterium tumefaciens gene transfer: How a plant pathogen hacks the nuclei of plant and nonplant organisms. Phytopathology 105:1288-1301.

Agrobacterium species are soilborne gram-negative bacteria exhibiting predominantly a saprophytic lifestyle. Only a few of these species are capable of parasitic growth on plants, causing either hairy root or crown gall diseases. The core of the infection strategy of pathogenic Agrobacteria is a genetic transformation of the host cell, via stable integration into the host genome of a DNA fragment called T-DNA. This genetic transformation results in oncogenic reprogramming of the host to the benefit of the pathogen. This unique ability of interkingdom DNA transfer was largely used as a tool for genetic engineering. Thus, the artificial host range of Agrobacterium is continuously expanding and includes plant and nonplant organisms. The increasing availability of genomic tools encouraged genome-wide surveys of T-DNA tagged libraries, and the pattern of T-DNA integration in eukaryotic genomes was studied. Therefore, data have been collected in numerous laboratories to attain a better understanding of T-DNA integration mechanisms and potential biases. This review focuses on the intranuclear mechanisms necessary for proper targeting and stable expression of Agrobacterium oncogenic T-DNA in the host cell. More specifically, the role of genome features and the putative involvement of host's transcriptional machinery in relation to the T-DNA integration and effects on gene expression are discussed. Also, the mechanisms underlying T-DNA integration into specific genome compartments is reviewed, and a theoretical model for T-DNA intranuclear targeting is presented.
\end{abstract}

Agrobacterium species are soilborne gram-negative bacteria exhibiting predominantly a saprophytic lifestyle. Only a few of these species are capable of parasitic growth on plants, causing either hairy root disease (A. rhizogenes) or crown gall disease (A. tumefaciens, A. rubi, and A. vitis). Both diseases are characterized by neoplastic growth at the site of infection, resulting from oncogenic transformation of the plant cell (Escobar and Dandekar 2003). In nature, wounded tissues are preferred entry sites for Agrobacterium species (Braun1952). In such damaged tissues, phenolic compounds accumulate in the subepidermal layer where they play a protective role against threatening organisms (Bhattacharya et al. 2010). Interestingly, some of these protective compounds (e.g., acetosyringone and $\alpha$-hydroxy-acetosyringone) are essential for the activation of a series of bacterial virulence (vir) genes, including the plasmid-borne VirA and VirG (Stachel et al. 1985; Stachel and Nester 1986), which initiate host-pathogen recognition and pathogenesis. Besides phenolic compounds, sugars such as

Corresponding author: M. Meyer; E-mail address: mmeyer@versailles.inra.fr

http://dx.doi.org/10.1094/PHYTO-12-14-0380-RVW

(C) 2015 The American Phytopathological Society aldose monosaccharides can also activate bacterial vir genes, but in a less effective fashion (Cangelosi et al. 1990). In addition, several chromosomally encoded genes such as $C h v G$ and $C h v I$, which encode a two-component $\mathrm{pH}$-sensing system, are required for vir gene expression and virulence (Li et al. 2002).

Most vir genes are located on a large resident element (e.g., pTiSakura, $200 \mathrm{~kb}$ [Suzuki et al. 2000]; pTiBo542, $250 \mathrm{~kb}$ [Komari et al. 1986]) termed Ri-plasmid in the root inducing A. rhizogenes and Ti-plasmid in tumor-inducing Agrobacteria such as A. tumefaciens (Fig. 1). Ri- and Ti-plasmids are necessary and sufficient for transferring virulence to nonpathogenic Agrobacteria from the same species or from a different species (Broothaerts et al. 2005; Hooykaas et al. 1977; Teyssier-Cuvelle et al. 2004). In particular, introduction of Ti-plasmids into nonpathogenic Rhizobium and Phyllobacterium spp. was sufficient to convert these species to pathogenic tumor-forming bacteria (Broothaerts et al. 2005; Teyssier-Cuvelle et al. 2004). Of interest to our review, Tiplasmids from A. tumefaciens typically contain two functionally distinct regions: the Vir region harboring the vir genes necessary for virulence and the T-DNA region to be transferred to the plant nucleus and integrated into the genome. The core of the bacterial infection strategy is thus a genetic transformation of the host cell via 
a series of coordinated interactions. The whole process includes (i) attachment of Agrobacteria to the host cell, (ii) processing and import of the T-DNA into the host cell via a type IV secretion system, (iii) molecular motor-mediated transport of the T-DNA to the nucleus, and (iv) nuclear import and targeting to host chromosomes (Citovsky et al. 2007). Eventually, proper integration of the T-DNA, in a region suitable for gene expression, leads to metabolic reprogramming of the cell in favor of the pathogen.

Since the early 1990s, the artificial host range of Agrobacterium species has expanded continuously in the laboratory for biotechnological purposes. Several nonplant organisms such as yeast (Bundock et al. 1995; Piers et al. 1996), filamentous fungi (Blaise et al. 2007; de Groot et al. 1998; Michielse et al. 2005), and human cells (Kunik et al. 2001) were successfully transformed with biotechnologically engineered Agrobacteria. The increasing availability of genomic tools encouraged genome-wide surveys of T-DNA tagged libraries, and the pattern of T-DNA integration in eukaryotic genomes was studied in plants such as Arabidopsis thaliana and Oryza sativa (Alonso et al. 2003; Schneeberger et al. 2005; Szabados et al. 2002; Zhang et al. 2007) as well as in nonplant organisms such as the ascomycetes Magnaporthe oryzae and Leptosphaeria maculans (Bourras et al. 2012; Choi et al. 2007). Therefore, data were made available to understand T-DNA integration mechanisms and potential biases.

In this review, we summarize some of the most sophisticated and highly evolved mechanisms used by A. tumefaciens to manipulate largely conserved cellular activities in Eukaryotes. In the first part of this review, we will briefly introduce general aspects of Agrobacterium's transfection biology to provide a context for T-DNA transfer. Then, we will focus on what probably is the most interactive step of A. tumefaciens transfection, T-DNA intranuclear targeting. More specifically, the role of genome structure, DNA repair, and gene transcription machinery from the host is reviewed. In particular, the factors influencing T-DNA integration into

\section{FIGURE 1}

Schematic representation of the tumor inducing plasmid from Agrobacterium tumefaciens. The Vir region is indicated including the location

of VirE2, VirD2, and VirF (blue boxes). The T-DNA region is indicated including predicted open reading frames (green boxes) and the left border (LB) and right border (RB) repeats. LB sequence microhomologies to the consensus sequence of core promoter motifs CAT-Box, Initiator, and TATA-Box are indicated. Origin of DNA replication (oriV, oriT, RB) and replication termination signal (LB) are indicated. Plasmid structure was adapted from Suzuki et al. (2000). LB sequence microhomologies to core promoter motifs were adapted from Bourras et al. (2012). specific genome compartments are discussed. Finally, we will propose a series of simple and adaptable theoretical models, where we reduce the complexity of T-DNA intranuclear targeting to the most relevant explanatory factors.

\section{T-DNA AND AGROBACTERIUM TUMORIGENESIS}

A. tumefaciens tumorigenesis requires proper expression of tumorigenic genes inside the host cell. These genes are specifically encoded by the T-DNA, a mobile segment of the Ti-plasmid delineated by two imperfect 25-bp direct-repeats termed the left border (LB) and the right border (RB) (Fig. 1). The T-DNA sequence exhibits eukaryotic core promoter elements that are unusual for a prokaryote (Barker et al. 1983). Of these, the polyadenylation signal, TATA box, and CAAT box motifs are thought to ensure proper transcription of the genes encoded by the T-DNA within eukaryotic hosts. The T-DNA 3' LB also harbors intriguing microhomologies with core promoter elements including TATA, CAAT, and initiator motifs (Fig. 1; Bourras et al. 2012). Microhomologies between T-DNA preinsertion sites in the host genome and T-DNA borders were also reported in plants and in fungi (Bourras et al. 2012; Brunaud et al. 2002). One hypothesis is that these sequences are involved in the annealing of the T-DNA to the host genomic DNA, probably with a preference for gene promoters where such motifs are likely present (Bourras et al. 2012; Brunaud et al. 2002; Tzfira et al. 2004a). Taken together, homologies and microhomologies with eukaryotic promoters could be regarded as a sophisticated sequence engineering that is probably meant to increase the chances for T-DNA-encoded genes to be expressed, either by providing a eukaryotic-like promoter or by favoring T-DNA annealing and integration into gene promoters.

Genes encoded by the T-DNA are grouped into two distinct classes as a function of their role in tumorigenesis. The first class of oncogenes encodes enzymes such as tryptophan mono-oxygenase and indoleacetamide hydrolase, which subvert plant auxin and

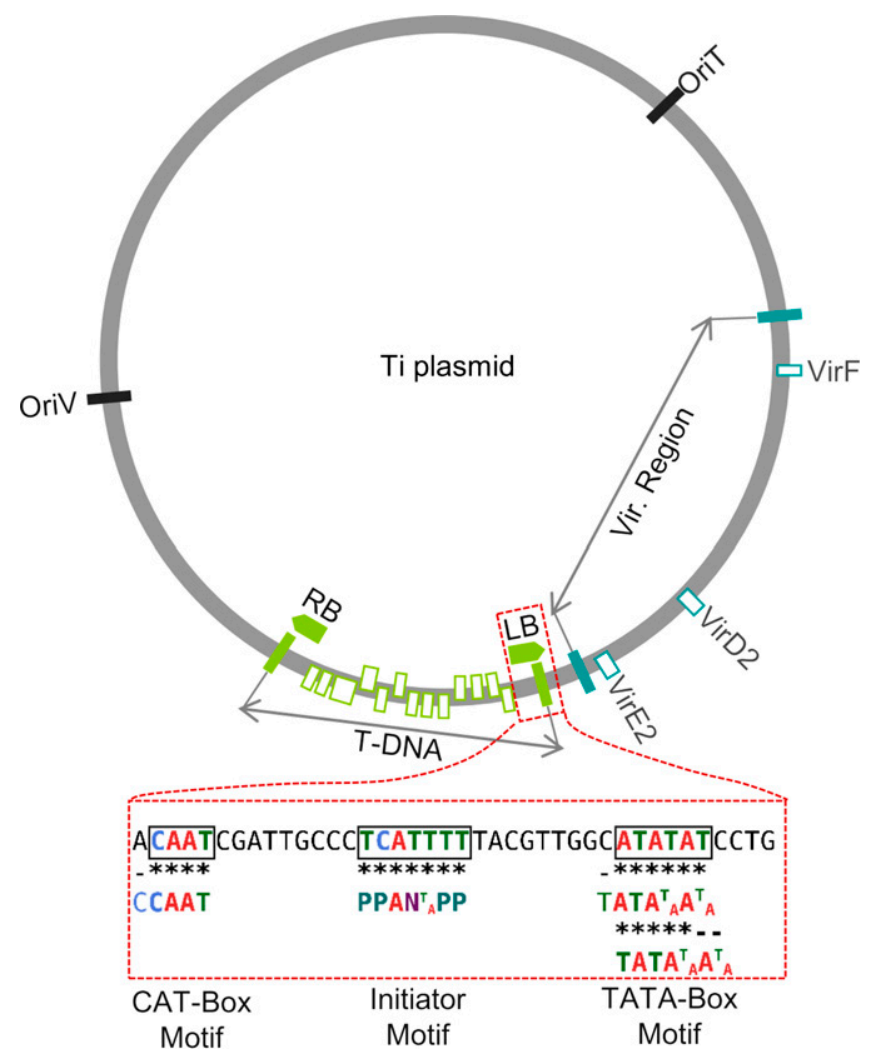


cytokinin hormone biosynthesis to generate the characteristic tumor swellings (Akiyoshi et al. 1984; Buchmann et al. 1985). The second class of genes direct cellular metabolism toward the production of amino acid and sugar derivatives called opines, which serve the colonizing bacteria a source of carbon and energy and, in some cases, a source of nitrogen and phosphorous (Kim and Farrand 1996). These chemically diverse metabolites, which occur rarely in nature, are a source of nutrients for Agrobacterium spp. (Guyon et al. 1980; Moore et al. 1997; Palanichelvam and Veluthambi 1996). Thus, T-DNA-directed opine biosynthesis, a process which creates a suitable environment for bacterial proliferation, has emerged as a central concept to the evolution of $A$. tumefaciens as a plant pathogen (Guyon et al. 1980; Palanichelvam and Veluthambi 1996). Another interesting aspect of pathogen-directed opine biosynthesis is that a given Agrobacterium strain is only capable of inducing and up-taking a few variants among at least 20 different opines that have been characterized (Dessaux et al. 1993; Winans 1992). Thus, the natural diversity of opines creates the conditions for the emergence of ecological niches within infected tissues, therefore providing inter- and intraspecies selective advantages (Pitzschke and Hirt 2010; Winans 1992).

\section{CHROMATIN-TARGETING MODELS AND BIASES}

Agrobacteria evolved a sophisticated transfection mechanism consisting of an interactive version of the T-DNA called the T-complex (Citovsky et al. 1997; Tzfira et al. 2004a). The formation of the T-complex is initiated immediately after induction of vir genes. Of these, the products of VirD1 and VirD2 form a sitespecific endonuclease complex that releases the T-DNA segment in a single-stranded conformation termed the T-strand. This singlestrand DNA fragment, covalently attached to VirD2 at its 5' end, enters the host cell through the VirB/VirD4 type IV bacterial secretion system (Fronzes et al. 2009). This translocation system is composed of 11 VirB proteins synthesized from the virB operon and the VirD4 subunit from the separate virD operon (Christie et al. 2005). In addition to the T-strand, several bacterial effectors such as VirE2, VirE3, VirF, and VirD5 are also exported to the host cell through the VirB/VirD4 system. Immediately after VirD2-T-strand primary complex entry to the host cell, it is coated with several VirE2 proteins (Fig. 2) to form a solid coiled filament, the T-complex (Abu-Arish et al. 2004; Bharat et al. 2013; Citovsky et al. 1997; Volokhina et al. 2011).

The T-complex conformation is maintained during the journey of the T-DNA inside the host cell until its anchorage to chromatin in a process relying on the host machinery (Gelvin 2010). The coating proteins VirD2 and VirE2 interact with various host proteins to mediate proper targeting to the chromatin (Eckardt 2004; Gelvin 2010). Here, we will focus on three host proteins and their cognate interactors that we propose as being (i) sufficient for reaching a reasonable understanding of this complex mechanism, and (ii) sufficient for building a series of simple and adaptable models for T-DNA intranuclear targeting in plant and nonplant organisms. Two of these host factors are the TATA box binding protein (TBP) and
FIGURE 2

Proposed models for the anchorage of the T-complex in gene promoter regions of plant and nonplant organisms. Here, we propose different models as possible explanations for T-DNA integration in gene promoter regions in plant and nonplant organisms. A,

In this model, we propose that the interaction between the bacterial virulence effector VirD2 and the host proteins CAK and TBP might be sufficient for proper anchorage of the T-complex to gene promoters (text provides details on CAK and TBP). Since CAK and TBP are widely conserved proteins among eukaryotes, model $\mathrm{A}$ is also proposed as a possible

explanation to transkingdom T-DNA transfer capabilities of Agrobacterium tumefaciens. By contrast to model A, models $\mathbf{B}$ and $\mathbf{C}$ account for the presence of plant-specific factors (here exemplified by VIP1, text provides details) capable of mediating the anchorage of the T-complex to gene promoters, independently $\mathrm{B}$

or in coordination $C$ with CAK and TBP. In $B$, we propose that the anchorage of the T-complex in the vicinity of gene promoters can be mediated by histone-binding factors from the host (here exemplified by VIP1), interacting with the T-complex via VirE2 and in a VirD2 independent fashion. Finally, a coordinated interaction between models $A$ and $B$ in plants is proposed in $\mathrm{C}$. Here, an additional layer of complexity is also added, where specific DNA motifs in promoter regions are involved (here exemplified by a VIP1 re-

sponse element [VRE], a VIP1 binding motif that occurs in promoters of stress responsive genes). We propose that such complex situations probably occur only in plants, based on the assumption of a long coevolution between Agrobacterium and natural plant hosts, which is a quite different context compared with artificial nonplant hosts.

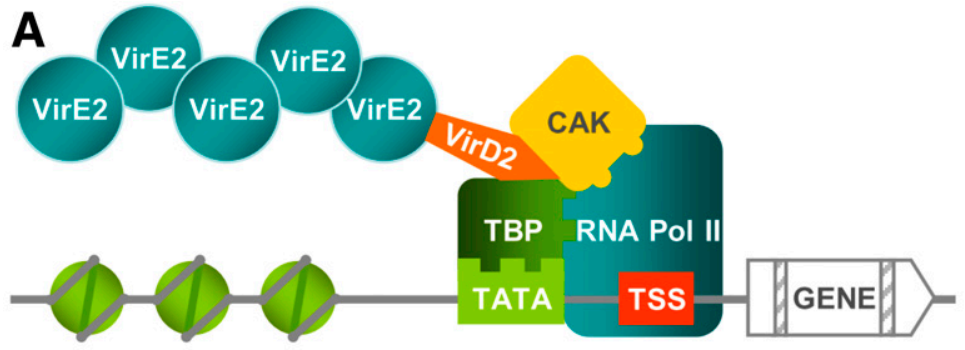

B
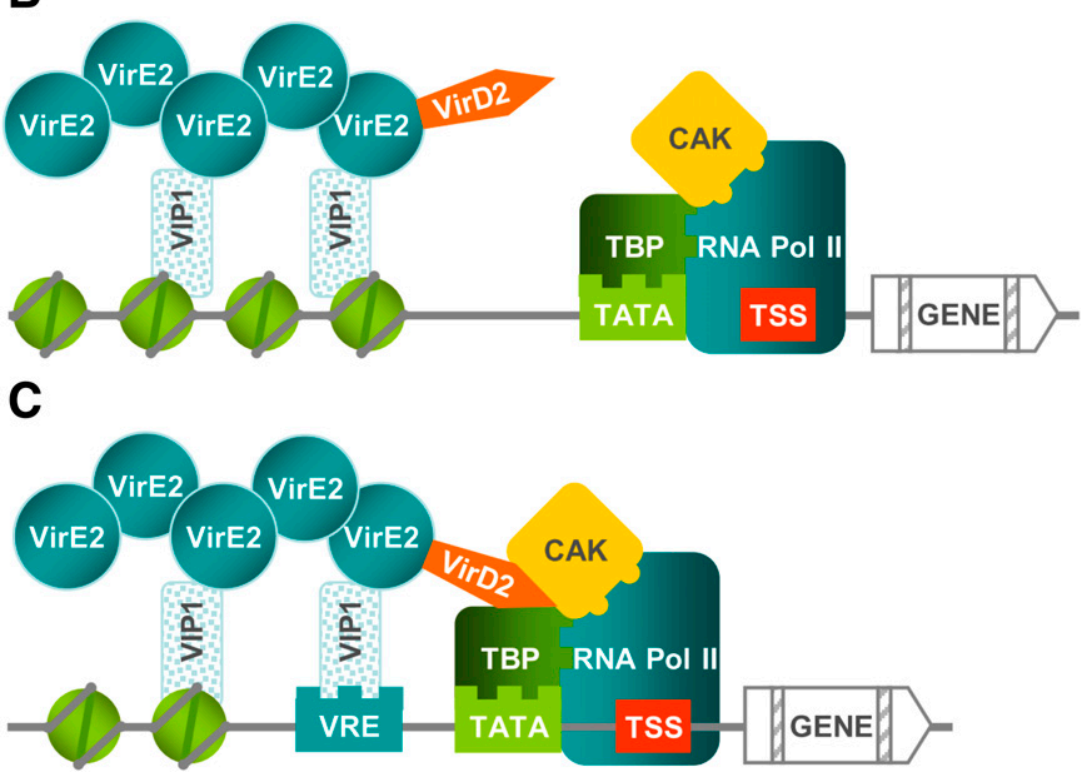
a cyclin-dependent kinase-activating kinase (CAK) (Bako et al. 2003). Both interact with RNA Pol II, and both are conserved proteins among eukaryotes. TBP and CAK associate with VirD2 and are thought to mediate an interaction between the T-complex and the transcription machinery (Bako et al. 2003). The third host factor is the VirE2-interacting protein 1 (VIP1), a stress-responsive bZip transcription factor thought to mediate an interaction between the T-complex and plant nucleosomes (Liu et al. 2010; Loyter et al. 2005; Tzfira et al. 2001). Although accumulating evidence moderates the importance of VIP1 in transfection and suggests that other bacterial proteins might be as important for nuclear import and targeting of the T-complex (Shi et al. 2014; Wang et al. 2014; Wolterink-van Loo et al. 2015), VIP1 remains a unique example of a hub protein in host-pathogen interactions, thus of primary interest to our models.

The VirD2, CAK, TBP, RNA Pol II system. In higher eukaryotes, cell division is regulated at each stage of the cell cycle by cyclin-dependent protein kinases (CDK) whose activity is regulated by phosphorylation, which is catalyzed by a CDKactivating kinase (CAK). Analysis of plant CAK enzyme activities has demonstrated that they phosphorylate CDK2 in Arabidopsis and rice (Umeda et al. 2005; Yamaguchi et al. 1998) and target the C-terminal domain (CTD) of the largest subunit of RNA Polymerase II (Bako et al. 2003; Umeda et al. 2005; Yamaguchi et al. 1998). This phosphorylation is crucial for transcription initiation (Mosley et al. 2009) which indicates that plant CAKs play not only a role in cell cycle regulation but are also involved in activating gene transcription. Interestingly, a phosphorylation of VirD2 by CAK was demonstrated in nuclei of alfalfa protoplasts (Bako et al. 2003). Assuming CAK function is not disturbed by VirD2, this interaction possibly targets the T-DNA to transcriptionally active chromatin, where specific interactions between CAK and RNA Pol II largest subunit are required. It also raises the hypothesis that RNA Pol II activity can possibly determine the locus to which the T-complex is targeted. At present, little is known about the impact of RNA Pol II activity on the targeting of the T-complex to chromatin.

RNA Pol II is a widely conserved eukaryotic enzyme that catalyzes transcription as part of a larger structure called the preinitiation complex (PIC), which binds to core promoters of genes. VirD2 can also associate with TBP which binds to the TATA box core promoter element (Fig. 2; Bako et al. 2003), and whose recognition nucleates the assembly of the PIC (Smale and Kadonaga
2003). Initial PIC binding to promoters is unstable, requiring up to 60 proteins to assemble at the promoter to ensure stable binding and transcription initiation (Dvir et al. 2001; Kim et al. 2000). Here, it is still unknown if the association of VirD2 with CAK and TBP has an impact on the assembly and stabilization of PIC and how these interactions may affect further steps of T-DNA integration. One hypothesis is that transcription initiation is disturbed by the presence of the T-complex, somehow attached to RNA Pol II in the promoter, where up to 60 additional proteins might assemble to form the PIC. A model accounting for such a scenario, with possible involvement of steric encumbrance in the promoter, is depicted in Figure 3.

Recent studies of genome-wide distribution of RNA Pol II showed frequent localization to promoters of nonexpressed genes, a phenomenon commonly termed stalling, likely to be involved in gene regulation (Guenther et al. 2007; Storz et al. 2005; Zeitlinger et al. 2007). Up to $30 \%$ of all genes in eukaryotic genomes can contain RNA Pol II permanently bound to their promoter (Core et al. 2008; Zeitlinger et al. 2007). Consequently, a putative CAK and/or TBP mediated association between VirD2 and RNA Pol II raises another hypothesis that RNA Pol II "stalling" activity can target the T-complex also to transcriptionally repressed regions. Thus, a model where T-DNA targeting partially depends on RNA Pol II activity would provide a possible explanation for (i) T-DNA insertions in transcriptionally active regions where RNA Pol II is engaged in gene transcription, (ii) T-DNA insertions in transcriptionally inactive regions where RNA Pol II is stalled, (iii) the diversity of expression profiles of T-DNA tagged genes, where T-DNA integrations were also found in loci that were not expressed under experimental conditions (Bourras et al. 2012; Zhang et al. 2007), and (iv) frequent T-DNA insertions in gene promoters, the primary binding site of RNA Pol II (Alonso et al. 2003; Bourras et al. 2012; Schneeberger et al. 2005; Szabados et al. 2002; Zhang et al. 2007).

The two-component system VirE2-VIP. In plants, the T-complex can be anchored to chromatin via the interaction between the VirE2 coating proteins and VIP1. This plant bZip transcription factor is thought to be involved in nuclear import of the T-complex and to mediate an interaction between the T-complex and core histones (Li et al. 2005; Loyter et al. 2005) (Fig. 2). An interaction between VirE2-VIP1 was observed in the cytoplasm and the nucleus, which indicates the contribution of VIP1 to transport and nuclear import

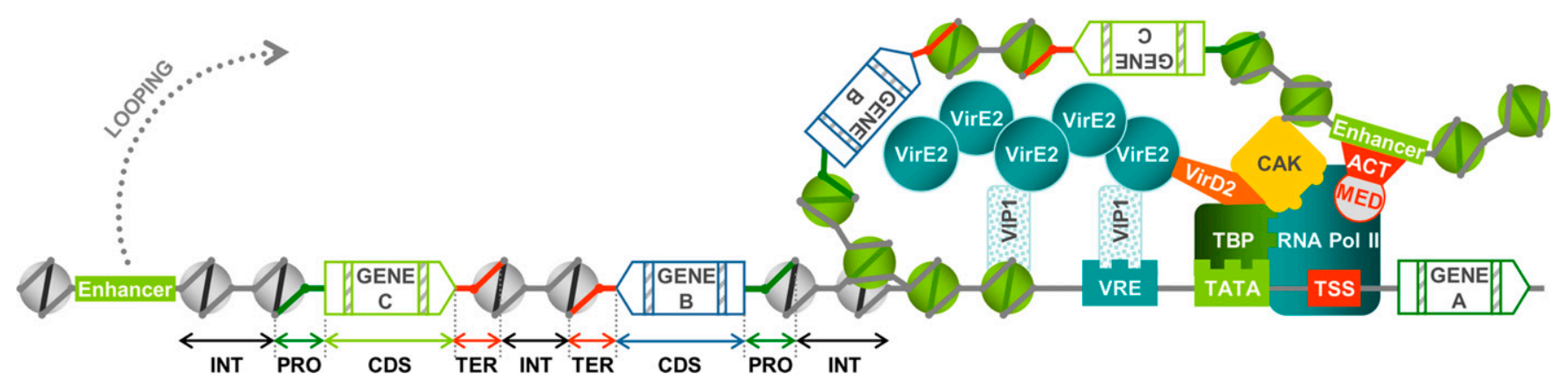

FIGURE 3

A proposed model for the accessibility of various genome compartments to the T-DNA following anchorage to a promoter region. The hypothesis depicted in this model is that T-DNA could virtually access all genome compartments from a primary anchorage of T-complex to a gene promoter region. In this hypothesis, a DNA loop is formed for enhancer-mediated activation of RNA Pol II while the T-complex is anchored to gene promoter. This activation also involves the activator (ACT) and the mediator (MED) proteins at transcription start site (TSS). Here, we assume that the presence of the T-complex is not anticipated by the transcription machinery. Thus, we propose that the T-complex disturbs transcription initiation by causing steric encumbrance at the promoter region and/or by disturbing RNA Pol II (indirectly attached to the T-complex via CAK, TBP, and VirD2). One hypothesis is that in the process of transcription initiation, at the steps of looping and/or promoter escape by RNA Pol II, DNA damage occurs, thus providing possible sites for T-DNA integration in the looping regions or the promoter, respectively. In addition to the promoter (PRO), DNA damage in the looping region could possibly provide access to various genome compartment such as terminator regions (TER), gene coding sequences including introns (CDS), and intergenic regions (INT), depending on the gene content of the looping DNA. 
of the T-complex (Shi et al. 2014; Tzfira et al. 2004a; Wang et al. 2014). It was also shown that the VirE2 binding sites with VIP1 were distinctly different from the VirE2 binding site with DNA, thus providing a molecular explanation for the VirE2-VIP1 interaction (Maes et al. 2014). Earlier studies have demonstrated that sequence alteration or silencing of VIP1 in plants lead to deficiency in stable transformation, whereas transformation efficiency was enhanced by VIP1 overexpression. This strongly supports the hypothesis that VIP1 is involved in T-DNA integration ( $\mathrm{Li}$ et al. 2005; Tzfira et al. 2001, 2002). Contrasting with these results, cases where overexpression of VIP1 had no dramatic consequences on transfection were also reported (Shi et al. 2014). Here, it is important to look at this data also from the perspective of a functional analysis of a transcription factor. In particular, overexpression of a transcription factor commonly results in a variety of effects including gain of resistance to pathogens (Zhang 2003). This is particularly relevant for VIP1, since it is only expressed at low levels and specifically associated with plant stress response and immunity signaling (Lacroix and Citovsky 2013a; Pitzschke et al. 2009; Tsugama et al. 2012, 2014).

VIP1 as a link to stress response, plant immunity, and osmoregulation. VIP1 is a stress-related bZIP transcription factor that belongs to the subgroup I of the bZIP family of A. thaliana (Jakoby et al. 2002). VIP1 is associated with stress response and plant immunity signaling, and binds a DNA motif (ACNGCT) termed VIP1 response element (VRE) that occurs frequently in stress responsive genes (Lacroix and Citovsky 2013a; Pitzschke et al. 2009; Tsugama et al. 2012, 2014). Therefore, the VirE2-VIP1 interaction could possibly favor the targeting of the T-complex to the promoters of the genes regulated by VIP1. Under this hypothesis, VIP1-mediated targeting of the T-complex could be regarded as a sophisticated strategy, where the pathogen hijacks plant immunity and stress response signaling to the benefit of transfection (Lacroix and Citovsky 2013b; Liu et al. 2010).

VIP1 and chromatin. VIP1 can also form homomultimers and bind via the C-terminal region to chromatin ( $\mathrm{Li}$ et al. 2005; Loyter et al. 2005; Yi et al. 2006). In planta, an interaction between VIP1 and a histone $\mathrm{H} 2 \mathrm{~A}$ variant (H2A-1) was detected in the nuclei of Arabidopsis (Li et al. 2005; Loyter et al. 2005). In vitro, VIP1 can bind to the four histone constituents of chromatin $(\mathrm{H} 2 \mathrm{~A}, \mathrm{H} 2 \mathrm{~B}, \mathrm{H} 3$, and H4) (Loyter et al. 2005) and can function as a bridge between VirE2 alone or bound to ssDNA and plant nucleosomes (Lacroix et al. 2008). These observations strongly support the hypothesis that VIP1 bridges the T-complex to chromatin.

The importance of T-complex association with plant nucleosomes was also demonstrated by the finding that silencing of histone $\mathrm{H} 3$ or sequence alteration of histone $\mathrm{H} 3$ and $\mathrm{H} 2 \mathrm{~A}-1$ result in deficiency in stable T-DNA integration (Anand et al. 2007a; Mysore et al. 2000; Zhu et al. 2003). By contrast, overexpression of several histone genes was shown to increase transformation efficiency in Arabidopsis (Tenea et al. 2009) Comparison of expression profiles of 7 out of 13 histone H2A genes of Arabidopsis also showed that only the $H 2 A-1$ exhibited increased expression in response to wounding or to Agrobacterium infection of root segments (Yi et al. 2002, 2006). Thus, changes in the level of expression of histone H2A-1 can probably affect chromatin structure and subsequent T-DNA integration. This hypothesis is supported by the fact that the silencing of four Arabidopsis chromatin-related genes including two histone acetyltransferases (HAF1 and HAG3), one histone deacetylase (HDT2), and one histone H3 chaperone (SGA1) severely impaired Agrobacterium-mediated root transformation (Crane and Gelvin 2007). Other candidates among chromatin structure and remodeling genes may also exist (Zhu et al. 2003).

VIP1 and F-box proteins. In eukaryotes, F-box proteins are subunits of the E3 ubiquitin ligases class referred to as Skp-CullinF-box (SCF) complexes, which are involved in selective protein degradation by the ubiquitin-proteasome pathway (del Pozo and Estelle 2000; Ho et al. 2008; Somers and Fujiwara 2009). The F-box protein subunit determines substrate specificity of the SCF complexes by recruiting a specific set of substrates for ubiquitination to the core complex (Ho et al. 2008; Somers and Fujiwara 2009). During transfection, VirF, a bacterial F-box protein, functions as a component of the SCF complex in the host (Tzfira et al. 2004b). Before integration of the T-DNA, VirF recognizes VIP1 and helps targeted proteolysis of the T-complex to remove VirE2 and VIP1 (Lacroix et al. 2008; Li et al. 2005; Loyter et al. 2005; Schrammeijer et al. 2001; Tzfira et al. 2004b,). In addition to VirF, the host F-box protein VBF (VIP1-binding F-box) is induced upon Agrobacterium infection (Zaltsman et al. 2010). Like VirF, VBF interacts with VIP1 and its associated VirE2, forming a ternary complex accumulating in the nucleus (Zaltsman et al. 2010). VBF also promotes VIP1dependent destabilization of VirE2 and complements tumor formation in an Agrobacterium strain lacking VirF (Zaltsman et al. 2010), which suggests that the plant-encoded VBF can functionally substitute for the bacterial virulence factor VirF. For the moment, it is not clear if $\mathrm{SCF}^{\mathrm{VBF}}$ - and the $\mathrm{SCF}^{\mathrm{VirF}}$-mediated proteasomal degradation take place through two distinct pathways (Schrammeijer et al. 2001; Zaltsman et al. 2010). Also, another layer of regulation was revealed by the finding that VirD5, which interacts with VIP1 in the nucleus (Wang et al. 2014), may regulate the degradation of VIP1 and VirE2 by preventing overly rapid processing through the $\mathrm{SCF}^{\mathrm{VirF}}$ pathway (Magori and Citovsky 2011; Wang et al. 2014).

VIP1 is not alone. The role of VIP1 in stable T-DNA transformation is challenged by the observation that plants in which VIP1 is silenced or interrupted by a T-DNA insertion were still able to develop tumors after infection by Agrobacterium. For the case where VIP1 was silenced in tobacco, a residual VIP1 expression can explain why about $10 \%$ of the plants still develop tumors after agroinfection (Tzfira et al. 2001). For the Arabidopsis vip1-1 T-DNA insertion line (Alonso et al. 2003), where $40 \%$ of root segments were still able to develop tumors, the mutation resulted in the expression of a truncated VIP1 protein corresponding to its first 244 amino acids (Shi et al. 2014). The critical observation is that this truncated version still contains three of the four VIP1-VirE2 binding sites (Maes et al. 2014). Therefore, one possible explanation is that the truncated protein would still interact with VirE2 and retain the ability to promote nuclear import of the T-complex. However, since the C-terminal end of VIP1 involved in binding to the H2A-1 histone is missing (Li et al. 2005), it is likely that the truncated VIP1 has lost the capacity to bridge the T-complex to chromatin. Thus, another possible explanation is that other proteins can substitute at least to a partial loss of VIP1 function. This hypothesis is supported by the recent discovery that VirD2 interacts with the histones H2A, H2B, H3, and H4 (Wolterink-van Loo et al. 2015), which completes a reasonable explanation for the vip1-1 mutant phenotype.

VIP1-VirE3 functional redundancy. Another example of functional redundancy between bacterial and host factors is provided by VirE3, a bacterial virulence factor capable of mediating nuclear import of the T-complex. Like VIP1, VirE3 forms a complex with VirE2 that localizes to the nucleus in plants (Lacroix et al. 2005). VirE3 also interacts with (i) a component of the COP9 signalosome, which is a multiprotein complex involved in plant development and defense against pathogens (Stratmann and Gusmaroli 2012), and (ii) a plant transcription factor from the general transcription factor II B (TFIIB) family, which binds to the TATA box and makes up the RNA polymerase II PIC (GarciaRodriguez et al. 2006). These properties of VirE3 are reminiscent of those described for VIP1, thus making VirE3 a plausible replacement for VIP1. This was partially demonstrated in tobacco, where transformation of VIP1 antisense plants with virE3 restored at least nuclear import of the T-complex (Lacroix et al. 2005).

VIP2 and T-DNA integration. Another possible alternative to VIP1 is the VirE2-interacting-protein 2 (VIP2). VIP2 is a putative transcription factor that belongs to the Negative Of TATA-less 
(NOT) domain-containing proteins, thought to be involved in transcriptional regulation, at least in yeast (Collart 2003; Collart and Timmers 2004). The involvement of VIP2 in Agrobacterium transfection and T-DNA integration was demonstrated in plants (Anand et al. 2007b). VIP2 is induced upon Agrobacterium infection and interacts with VirE2 both in vitro and in planta (Anand et al. 2007b). Transcriptional analyses of wild-type Arabidopsis and A. thaliana vip2 mutant indicated that VIP2 is involved in transcriptional regulation of histones or histone-associated proteins (Anand et al. 2007b). It now would be interesting to know if VIP2 is capable of bridging the T-complex to chromatin.

Locus bias in T-DNA targeting to chromatin. With the main exception of stalling RNA Pol II, the intrinsic functions of CAK, RNA Pol II, TBP, and VIP1 support the hypothesis that the gene promoters in transcriptionally active regions are preferred targets for the T-DNA. This hypothesis is substantiated by genome-wide studies of T-DNA mutant libraries showing that T-DNA integrations frequently occurs in gene promoter regions, and more globally in gene rich regions in plants (Alonso et al. 2003; Schneeberger et al. 2005; Szabados et al. 2002; Zhang et al. 2007) and fungi (Bourras et al. 2012; Choi et al. 2007). T-DNA insertions were also found in a variety of genomic compartments including coding regions (including introns), gene terminator sequences, intergenic spaces, heterochromatin like repeat-rich regions, and telomeres (Bourras et al. 2012; Choi et al. 2007). These results suggest that a primary or a preferred targeting of the T-complex to a gene promoter sequence does not necessarily result in T-DNA integration exclusively at this locus. Kim et al. (2007) proposed that preferred integration into generich regions could be an artifact resulting from screening of T-DNA mutagenized plants with selection-markers. However, Bourras et al. (2012) noticed a coincidence of T-DNA tag density and gene density between gene rich (GC-equilibrated) and gene poor (AT-rich) compartments of the isochore-structured genome of the ascomycete L. maculans. These AT-rich compartments behave as heterochromatin in L. maculans (Soyer et al. 2014) further substantiating a bias of integration between transcriptionally active euchromatin and transcriptionally inactive heterochromatin. Bourras et al. (2012) have also noticed that the functional profile of T-DNA targeted genes reflected to a certain extent the physiological state of a germinating conidium and thus the transcriptional activity at the time of transfection. These observations add to the complexity of T-DNA intranuclear-targeting, which depends on genome structure, transcriptional activity, and available interacting partners from the host.

\section{T-DNA INTEGRATION MODELS AND BIASES}

DNA double-strand breaks and T-DNA integration. In eukaryotes, DNA double-strand breaks (DSBs) can be induced in the genome by environmental DNA-damaging factors such as ionizing and UV radiation (Harper et al. 2010; Limoli et al. 2002) and genotoxic agents (Bosco et al. 2004). Various endogenous factors linked to cell activity can also lead to DNA damage. DSBs occur during largely conserved biological processes such as replication fork collapse and replication restart (Hanada et al. 2007), mitotic segregation of dicentric chromosomes (Acilan et al. 2007), and meiotic recombination (Keeney and Neale 2006). In budding yeast, meiotic DSB hotspots occur frequently in opened chromatin (Berchowitz et al. 2009), transcriptionally active promoters, telomeres, and centromeres (Blitzblau et al. 2007; Buhler et al. 2007). DSBs can also originate from transposon activity (Gasior et al. 2006) and DSB-induced gene conversion can occur in mating-type switching, at least in yeast (Klar et al. 1991).

DSBs are major targets for T-DNA integration (Tzfira et al. 2004a); however, the exact mechanism of DSB-mediated integration of the T-DNA remains poorly understood. DSBs are a serious threat to genome integrity because they disrupt the continuity of the DNA molecule. To address this problem, at least three distinct DSB-repair mechanisms exist in eukaryotes: homologous recombination (HR), nonhomologous end joining (NHEJ), and microhomology-mediated end joining (MMEJ) (Jackson 2002; McVey and Lee 2008). Of these, NHEJ and HR were proposed to be the two main mechanisms mediating T-DNA integration by Tzfira et al. (2004a) and Citovsky et al. (2007). NHEJ and HR are commonly opposed as a template-independent and a homology-based pathways for DSB repair, respectively. NHEJ can take place throughout the cell cycle but is predominant during the G1 phase when HR is not efficient (Frank-Vaillant and Marcand 2002). NHEJ differs also from HR by its conceptual simplicity, since it consists of a straightforward religation of the DSB gap, while HR requires sequence homology between damaged DNA and the template DNA used to religate the gap (Bernstein and Rothstein 2009; Chilton and Que 2003; Dudas and Chovanec 2004). HR is mainly active during late S-G2 phases of cell cycle where sister chromatids mutually provide undamaged DNA templates to be used (Jackson 2002). It is thus referred to as an error-free mechanism of DSB repair. One particularity of HR mediated T-DNA integration is that the LB overhanging end is proposed to serve as a template and anneals to the host DNA. This would suggest that T-DNA can only integrate if there is enough sequence homology between the LB and the host DNA. Studies addressing the minimum amount of sequence homology required for HR have reported very different numbers, with as little as 6 bp in plants (Baur et al. 1990), 20 bp in yeast (Hua et al. 1997), and 14 bp in mammalian cells (Rubnitz and Subramani 1984). However, it has also been demonstrated that HR actually requires larger segments of homologous sequences to be efficient (Barzel and Kupiec 2008; Baur et al. 1990; Hua et al. 1997; Rubnitz and Subramani 1984;). In this context, it seems unlikely that T-DNA integration via HR is the most prevalent mechanism for integration. It is also unlikely that HR is the mechanism taking advantage of LB sequence imperfect short homologies in eukaryotic core promoter elements.

T-DNA integration via MMEJ: Is HR still relevant? Recently, a third mechanism for DSB-repair, referred to as MMEJ, was proposed (McVey and Lee 2008). In yeast, MMEJ was described as a KU-independent mechanism to repair double-strand breaks lacking overlapping end sequences (Ma et al. 2003). As the MMEJ mechanism includes several HR and NHEJ components, it can thus be hypothesized that a cell capable of both HR and NHEJ may also be capable of MMEJ repair. It was also postulated that MMEJ may function after critical failure of HR and NHEJ using available components of both machineries (McVey and Lee 2008). One feature of MMEJ that is relevant to T-DNA integration is the use of 5- to 25-bp microhomologous sequences to anneal the template DNA to the overhanging DSB ends (Fig. 4). Thus, we propose that MMEJ mediated T-DNA integration is probably a more likely T-DNA integration mechanism than HR (Fig. 4). This is also in agreement with previous reports of frequent short homologies between the T-DNA sequence and T-DNA preinsertion sites (Bourras et al. 2012; Brunaud et al. 2002) which seems to be unlikely to be enough overlap for actual integration via HR (Barzel and Kupiec 2008; Baur et al. 1990; Hua et al. 1997; Rubnitz and Subramani 1984).

T-DNA integration as a coproduct of DNA damage and repair. DSB repair efficiency varies along chromosomes as a function of gene content and chromatin state. For instance, DSB repair is deficient in telomere regions and packed heterochromatin in comparison with gene-rich chromatin (Chambers and Downs 2007; Ricchetti et al. 2003). Hence, T-DNA integration, which relies on DSB repair machinery, could also probably depend on DSB repair efficiency along chromosomes or between different chromosomal landscapes. Interestingly, the predominance of DSBs in open chromatin and transcriptionally active promoters fits with frequent mapping of the T-DNA to promoters and transcriptionally active 
regions (Alonso et al. 2003; Bourras et al. 2012; Szabados et al. 2002; Zhang et al. 2007).

In plants and fungi, promoter regions harbor a GC-compositional strand bias (GC-skew) that reaches its maximum near transcription start site (TSS) (Fujimori et al. 2005; Tatarinova et al. 2003). Bourras et al. (2012) showed that GC-skew and T-DNA tags density in promoter regions increase gradually toward gene start codon, with a peak of T-DNA tags density close to the peak of GC-skew. This skew is generated by cytosine deamination during the start of DNA transcription when methylated cytosine and cytosine in promoter regions are converted to thymine and uridine, respectively (Metivier et al. 2008). As a result, T/G or U/G mispairs are generated and the removal of these base-base mismatches involve two eukaryotic cellular DNA repair pathways named base excision repair (BER) and mismatch repair (MMR) (Balajee and Bohr 2000; Pena-Diaz and
Jiricny 2012). Recently, it was shown that BER and MMR can interfere with each other as the nick generated by BER can be used as an entry point for exonuclease 1 (EXO1), thus likely leading to a DSB that could possibly result in T-DNA integration. It is interesting to notice that another way of T-DNA integration remains possible by microhomology-dependent annealing of the T-strand $3^{\prime}$ end to the 150-nucleotide-long single-stranded genomic region generated by the EXO1 activity. Sequence homology between T-DNA 3' LB and core promoter elements (Fig. 1; Bourras et al. 2012) may play a role in annealing, which would provide a possible explanation for preferential targeting of the T-DNA to sequences near the TSS (Bourras et al. 2012). This hypothesis would apply also to the single-strand gap-repair T-DNA integration model previously described by Tinland (1996).

Previous studies of genome-wide T-DNA tag distribution (Alonso et al. 2003; Bourras et al. 2012; Szabados et al. 2002;
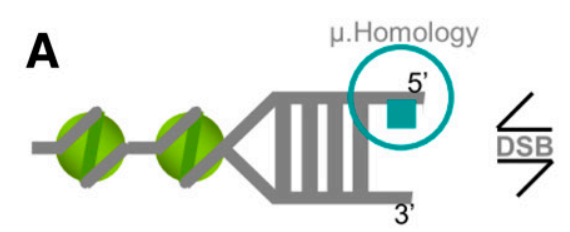

$\downarrow$

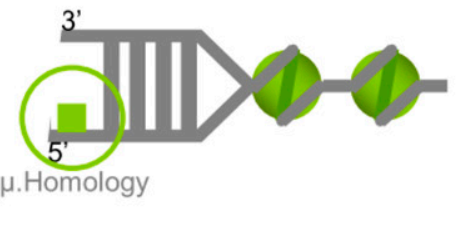

B
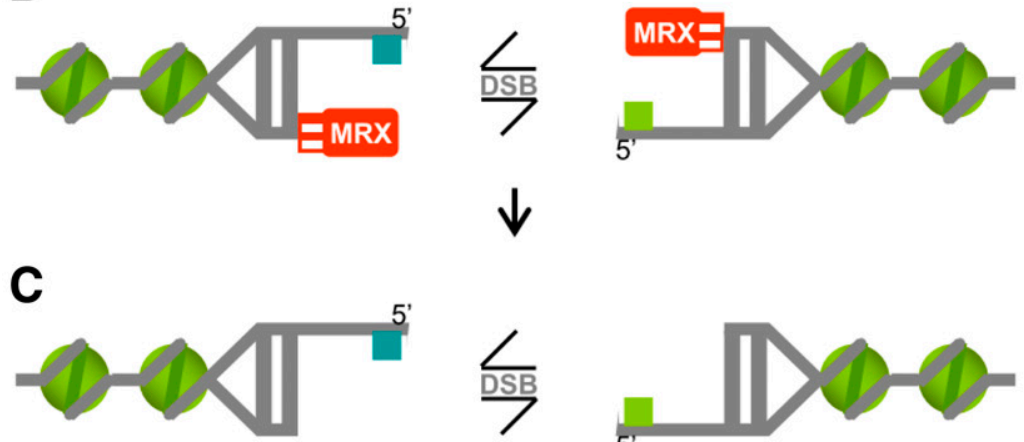

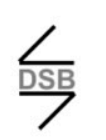

$\downarrow$

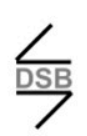

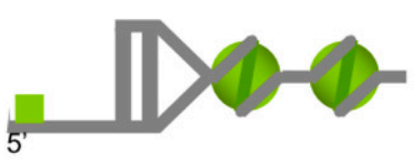
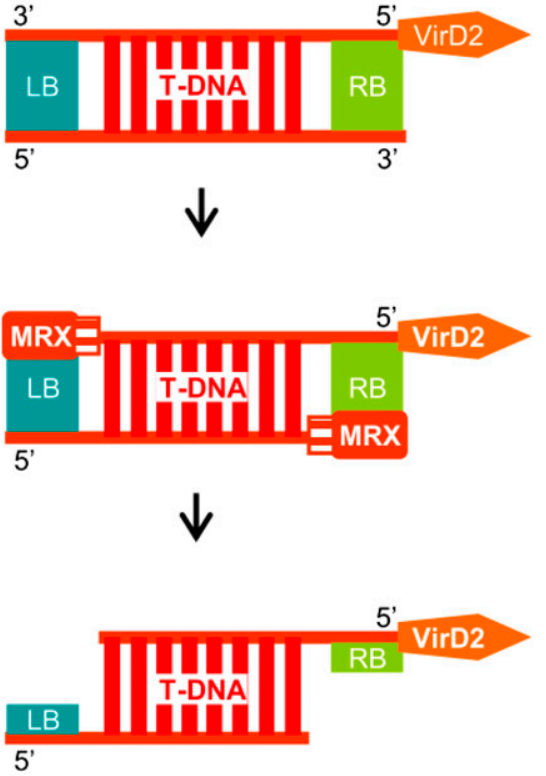

5

D
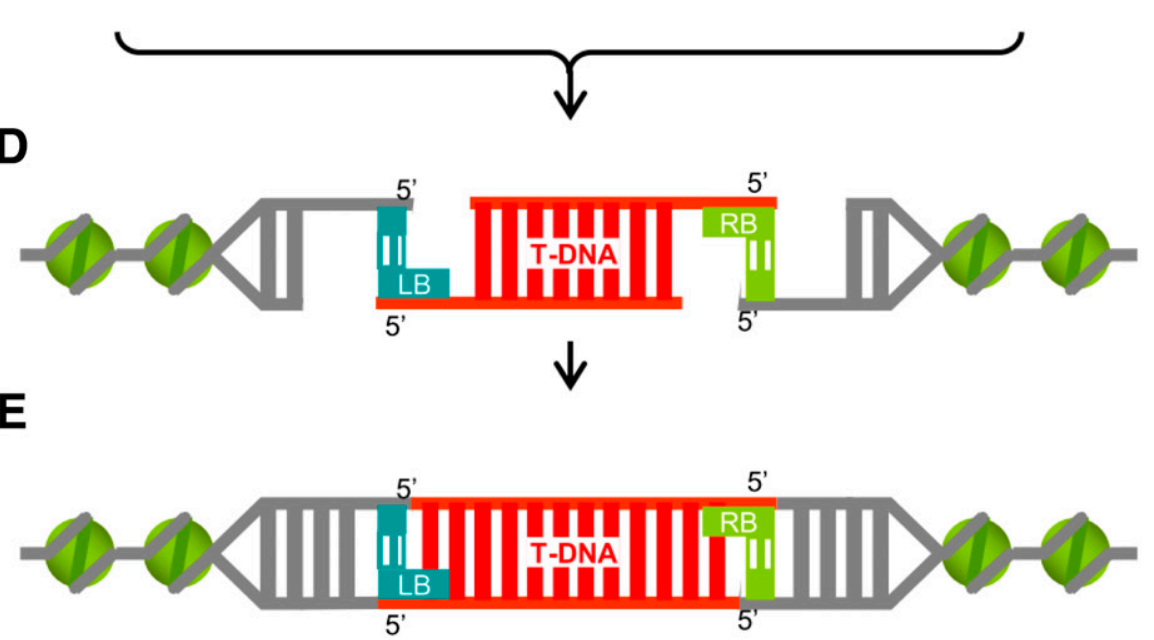

\section{FIGURE 4}

A proposed model for Agrobacterium tumefaciens T-DNA integration via the microhomology-mediated end joining pathway of DNA double strand break repair. A, T-DNA integration is initiated following a double-strand break (DSB) in the vicinity of the T-complex. DSB serves as a signal for T-strand uncoating and processing into double stranded T-DNA, with VirD2 remaining covalently attached to its 5' right border (RB) repeat. B, The 3' ends of the broken host DNA and Agrobacterium's T-DNA are processed by an endonucleolytic complex (here exemplified by the Mre11/Rad50/Xrs2 (MRX) complex from yeast), while VirD2 still protects the right border of the T-DNA. C, Resection by the MRX complex (or its equivalent in plants and mammals) produces free 5' tails at DSB site and leaves T-DNA LB and RB repeats overhanging. In contrast to the RB repeat (protected by VirD2), our hypothesis is that the unprotected left border is affected by endonucleases, which provides a possible explanation for sequence variability of the LB versus sequence conservation of the RB at T-DNA insertion sites. D, T-DNA border repeats anneal to DSB 5' ends at microhomologous sites, and the remaining noncomplementary DNA segments are trimmed. E, Finally, complementary strands are synthesized at the gaps. 
Zhang et al. 2007) reported a scarcity of T-DNA tags in heterochromatin and telomeres where DSBs occur frequently but repair is defective. T-DNA insertions in plants are commonly associated with major chromosomal translocations and rearrangements, a phenomenon that requires efficient DSBs repair (Clark and Krysan 2010; Majhi et al. 2014; Nacry et al. 1998; Zhu et al. 2010). DSB repair efficiency could be the ultimate decision maker for T-DNA integration to occur into one locus instead of the other. In addition, choices between different DSB repair mechanisms may occur depending on cell status, cell type, and specificities within a single species (Frank-Vaillant and Marcand 2002; Jackson 2002; Shrivastav et al. 2008). These data all concur to indicate that biases in T-DNA mapping are a coproduct of DSB mapping, the choice of the repair mechanism and repair efficiency.

\section{SUMMARIZING THE MODELS}

In an attempt to propose a series of simple and adaptable models for T-DNA intranuclear targeting, we have identified and used only a subset of the many factors involved in this very complex mechanism. Of these, VirD2, VirE2, VIP1, RNA Pol II, and the nucleosomes serve as building blocks for four proposed models hereafter referred to as pathways for T-DNA targeting (Table 1, Figs. 2, 3, and 5).

Pathway 1, VirD2-CAK-RNA Pol II. Pathway 1 is based on the VirD2-CAK-RNA Pol II interaction (Fig. 2A) which may target the T-complex preferentially to (i) gene promoters, when mRNA or ncRNA synthesis is imminent, and (ii) gene promoter and proximal promoter regions, permanently bound by stalled RNA Pol II. Our hypothesis is that the T-complex, solidly or transiently bound to CAK and/or RNA Pol II, causes steric encumbrance resulting in DNA damage when the activation loop is formed and/or when RNA Pol II engages promoter escape. This event gives the signal for further integration of the T-DNA in a locus close to the transcription start site (TSS), or virtually any DNA lesion occurring in the looping sequence (Fig. 3). In this model, we also assume that a link exists between a mechanism named transcription elongation coupled repair (TECR) and the chromatin targeting of the T-complex, and hypothesize that it could promote T-DNA integration outside promoter regions. TECR targets DNA alterations that interfere with the translocation of RNA Pol II through expressed genes (Hanawalt and Spivak 2008). TECR is thought to be initiated by stalled RNA Pol II elongation complex at DNA lesions which serves to recruit the repair machinery (Coin et al. 2008; Hanawalt and Spivak 2008; Svejstrup 2002; Svejstrup et al. 1995). In human and yeast cells, the association of TFIIH (a basal transcription factor associated to the RNA Pol II) with TECR-specific factors catalyzes the detachment of CAK from TFIIH and it is only once TECR is complete that CAK reassociates to TFIIH to promote resumption of transcription (Coin et al. 2008; Hanawalt and Spivak 2008; Svejstrup 2002; Svejstrup et al. 1995). If such a scenario is also verified for plants, one hypothesis is that CAK reassociation with TFIIH in the middle of an ongoing gene transcription is a possible scenario for T-DNA targeting in gene coding sequences.

Pathway 2, VirD2-TBP-RNA Pol II. The second pathway relies on the VirD2-TBP-RNA Pol II interaction (Fig. 2A) which is proposed to target the T-complex not only to TATA-containing promoters, which represent only $\sim 20 \%$ of yeast genes (Basehoar et al. 2004), but also to TATA-less promoters. Transcription from TATA-less promoters is also TBP dependent and the TBP recruitment is unlikely the rate-limiting step in PIC assembly at TATA-less promoters (Hampsey 1998). Moreover, a genomewide analysis performed to identify the distribution of TBP and six general transcription factors in yeast genes, indicated that these factors are found at the same relative distance from the TSS at promoters containing or lacking a TATA box (Venters and
Pugh 2009). Thus, the presence of a TATA box is not compulsory for PIC assembly at a fixed distance from the TSS. T-DNA integration via pathway 2 is proposed to occur preferentially in gene promoters and/or near the TSS, independently from the presence of a TATA box motif. Here, we propose the same scenario as in pathway 1 for DNA damage and further T-DNA integration (Fig. 3).

Pathway 3, VirE2-VIP1-nucleosome. Unlike pathways 1 and 2 , which can hypothetically operate in all eukaryotes, the two next pathways are presumably restricted to plants since they include VIP1. It has been suggested that VIP1 was implicated in chromatin decondensation (Avivi et al. 2004), thus pathway 3, which relies on a VirE2-VIP1-nucleosome interaction, is proposed to target the T-complex primarily to packed chromatin (Fig. 2B). In this scenario, the T-DNA has only secondary access to gene regulatory regions, assuming that the T-complex is anchored in a border zone between a histone-containing region capable of anchoring the T-complex and a histone-less region where transcription takes place.

Pathway 4, VirE2-VIP1-VRE motif. The fourth pathway relies on VirE2-VIP1-VRE motif interaction (Fig. 2C) and is proposed to direct the T-complex targeting preferentially to gene promoters containing the VRE regulatory motif. In this hypothesis, steric encumbrance of the promoter leads to DNA lesions and further T-DNA integration similarly to pathways 1 and 2 (Fig. 3). An implication of VIP2 in pathways 3 and 4 is also possible but remains to be evaluated.

In addition to these pathways, we propose that T-DNA mapping to different genome compartments is ultimately conditioned by the type of DNA repair mechanism leading to integration. Hypothetically, when integration is mediated by the template-independent NHEJ, the T-DNA could access all genome compartments. However, when it is mediated by HR, MMEJ or presumably BER and MMR, the availability of sufficient sequence homology between the T-DNA borders and DSB ends is a limiting factor. Thus, in this case, gene promoters could be preferred targets for integration, since T-DNA imperfect repeats harbor microhomologies to eukaryotic core promoter elements (Bourras et al. 2012). Eventually, T-DNA of a specific genome compartment will probably depend on the relative prevalence of template-independent versus homology-dependent pathways at the time of integration.

\section{ADDITIONAL LAYERS OF COMPLEXITY IN T-DNA BIOLOGY}

Cell type matters. Previous studies have also revealed that the type of transformed cells seems to be of utmost importance (Anand et al. 2007b; Mysore et al. 2000; Zhu et al. 2003). In particular, two Arabidopsis histones $\mathrm{H} 2 \mathrm{~A}-1$ and $\mathrm{H} 3$ tagged mutants were recalcitrant to Agrobacterium transformation by root inoculation (Anand et al. 2007b; Mysore et al. 2000; Zhu et al. 2003). Surprisingly, these plants were not deficient in T-DNA integration when vacuum infiltration of flowers were used (Mysore et al. 2000; Zhu et al. 2003). One possible explanation is that some of the host proteins required for T-DNA integration could be transcriptionally suppressed, biochemically inactivated or physically inaccessible to Agrobacterium, depending on the type of tissue. This is a challenging observation for the functional studies addressing the role of host proteins in transfection, where interactions are only assessed in roots. It would be interesting to determine if the experimental assessment of VIP1 contribution to transfection would yield similar contrasting results (Li et al. 2005; Shi et al. 2014; Tzfira et al. 2001, 2002) when transforming other tissues such as calli, immature embryos, pollen, shoot apex, floral organs, or seeds.

T-DNA integration via mammalian-like DSBs occurring in plants. Another point requiring investigation in plants and other eukaryotes concerns the mechanisms of T-DNA integration. In the promoters of transcriptionally active regions of plants, this process is probably connected to at least two DNA-repair mechanisms: BER 
TABLE 1

Summary of T-DNA intranuclear targeting proposed models and bias

\begin{tabular}{|c|c|c|c|c|c|c|c|}
\hline & \multicolumn{2}{|c|}{$\begin{array}{l}\text { Factors used in the proposed models of T-DNA } \\
\text { intranuclear targeting }\end{array}$} & & & & & \\
\hline & $\begin{array}{c}\text { Function in T-DNA } \\
\text { intranuclear targeting. } \\
\text { interaction sites/partners }\end{array}$ & $\begin{array}{l}\text { Function in the } \\
\text { host-interaction } \\
\text { sites/partners }\end{array}$ & \multicolumn{5}{|c|}{ Proposed models for T-DNA intranuclear targeting bias ${ }^{b}$} \\
\hline \multicolumn{8}{|c|}{ A. tumefaciens } \\
\hline VirD2 & $\begin{array}{l}\text { Coating of the } 5^{\prime} \text { end of the } \\
\text { T-strand. Protein } \\
\text { component of the } \\
\text { T-complex. Interaction } \\
\text { with CAK and TBP (Bako } \\
\text { et al. 2003; Fronzes et al. } \\
\text { 2009). Interaction with } \\
\text { histones (Wolterink-van } \\
\text { Loo et al. 2015). }\end{array}$ & - & 1 & 2 & & & $\begin{array}{l}\text { Anchorage of the } \\
\text { T-complex to } \\
\text { gene promoters. } \\
\text { Preferential targeting } \\
\text { of transcriptionally } \\
\text { active chromatin via } \\
\text { interaction with CAK } \\
\text { and TBP. }\end{array}$ \\
\hline VirE2 & $\begin{array}{l}\text { Coating of the T-strand. } \\
\text { Protein component of the } \\
\text { T-complex. Interaction } \\
\text { with VIP1 (Abu-Arish et al. } \\
\text { 2004; Citovsky et al. } \\
\text { 1997; Li et al. 2005; Maes } \\
\text { et al. 2014; Shi et al. } \\
\text { 2014; Tzfira et al. 2001, } \\
\text { 2002; Wang et al. 2014). }\end{array}$ & - & & & 3 & 4 & $\begin{array}{l}\text { Anchorage of the } \\
\text { T-complex to } \\
\text { chromatin. } \\
\text { Preferential targeting } \\
\text { of gene promoters via } \\
\text { interaction with } \\
\text { VIP1. }\end{array}$ \\
\hline \multicolumn{8}{|l|}{ Host } \\
\hline CAK & $\begin{array}{l}\text { Interaction with VirD2 (Bako } \\
\text { et al. 2003). }\end{array}$ & $\begin{array}{l}\text { Cyclin-dependent protein } \\
\text { kinase-activating kinase. Cell } \\
\text { division. Phosphorylation } \\
\text { of RNA Pol II largest } \\
\text { subunit. Transcription } \\
\text { initiation (Bako et al. } \\
\text { 2003; Mosley et al. 2009; } \\
\text { Umeda et al. 2005; } \\
\text { Yamaguchi et al. 1998). }\end{array}$ & 1 & & & & $\begin{array}{l}\text { Anchorage of the } \\
\text { T-complex to gene } \\
\text { promoters. } \\
\text { Preferential targeting } \\
\text { to transcriptionally } \\
\text { active chromatin. }\end{array}$ \\
\hline TBP & $\begin{array}{l}\text { Interaction with VirD2 (Bako } \\
\text { et al. 2003). }\end{array}$ & $\begin{array}{l}\text { Component of the } \\
\text { transcription preinitiation } \\
\text { complex. Transcription } \\
\text { initiation. binding to TATA } \\
\text { containing and TATA-less } \\
\text { promoters (Basehoar } \\
\text { et al. 2004; Hampsey } \\
\text { 1998; Venters and Pugh } \\
\text { 2009). }\end{array}$ & & 2 & & & $\begin{array}{l}\text { Anchorage of the } \\
\text { T-complex to } \\
\text { gene promoters. } \\
\text { Preferential targeting } \\
\text { to transcriptionally } \\
\text { active chromatin. }\end{array}$ \\
\hline
\end{tabular}

(continued on next page)

\footnotetext{
${ }^{a}$ We have reduced the complexity of T-DNA intranuclear targeting to eight factors defining four models. Two factors are from Agrobacterium tumefaciens and six are from the host. The role of these factors in targeting the T-complex and/or in the biology of the host is indicated.

${ }^{b}$ For each of the four proposed pathways (P.1, P.2, P.3, and P4), the factors used for building these models are indicated by $1,2,3$, and 4 , respectively. For each factor, a list of proposed integration bias is given, based on the information indicated.
}

and MMR. A third mechanism recently described in mammals might also operate in plants. It relies on a transient DNA topoisomerase II $\beta$ (TopoII $\beta$ )-mediated DSB required for transcriptional activation of estrogen-responsive genes by nuclear androgen and estrogen receptors (Haffner et al. 2010; Ju et al. 2006). In animal cells, the association between TopoII $\beta$ and DNA is impaired by an oxidative stress resulting in the activation of TopoII $\beta$-mediated DNA cleavage $(\mathrm{Li}$ et al. 1999; Mandraju et al. 2011). Acidic pH environment ( $\mathrm{pH} 5$ to 6) as well as DNA structural modifications (abasic sites) activate
TopoII $\beta$-mediated DNA cleavage. Strikingly, these conditions are also those that could prevail during plant infection by Agrobacterium: (i) an oxidative stress induced by the release of phenolic compounds in wounded cells, (ii) the production of reactive oxygen species and the induction of stress gene expression following the recognition of the bacterium by the plant cell, and (iii) acidic conditions found in the rhizosphere. Also, VIP1 from plants and nuclear receptor transcription factors from metazoans share common properties: (i) phosphorylation, (ii) nuclear translocation, 


\begin{tabular}{|c|c|c|c|c|c|c|c|}
\hline \multicolumn{8}{|c|}{$\begin{array}{c}\text { TABLE } 1 \\
\text { (continued from preceding page) } \\
\end{array}$} \\
\hline & \multicolumn{2}{|c|}{$\begin{array}{l}\text { Factors used in the proposed models of T-DNA } \\
\text { intranuclear targetinga }\end{array}$} & & & & & \\
\hline & $\begin{array}{c}\text { Function in T-DNA } \\
\text { intranuclear targeting. } \\
\text { interaction sites/partners }\end{array}$ & $\begin{array}{l}\text { Function in the } \\
\text { host-interaction } \\
\text { sites/partners }\end{array}$ & P.1 & P.2 & P.3 & P.4 & Proposed bias \\
\hline Nucleosome & $\begin{array}{l}\text { Binding affinity with VIP1. } \\
\text { Anchorage of the } \\
\text { T-complex via the VIP1- } \\
\text { VirE2 interaction (Tenea } \\
\text { et al. 2009; Ziemienowicz } \\
\text { et al. 2001). }\end{array}$ & $\begin{array}{l}\text { binding site for the bZIP } \\
\text { transcription factor VIP1 } \\
\text { (Li et al. 2005; Loyter } \\
\text { et al. 2005; Yi et al. 2006). }\end{array}$ & & & 3 & & - \\
\hline VIP1 & $\begin{array}{l}\text { VirE2-interacting protein } 1 . \\
\text { Interaction with VirE2 in } \\
\text { the cytoplasm and the } \\
\text { nucleus. Anchorage of the } \\
\text { T-complex to core } \\
\text { histones (Li et al. 2005; } \\
\text { Maes et al. 2014; } \\
\text { Shi et al. 2014; Tzfira et al. } \\
\text { 2001, 2002; Wang et al. } \\
\text { 2014). }\end{array}$ & $\begin{array}{l}\text { bZIP transcription factor. } \\
\text { Regulation of stress } \\
\text { responsive genes. } \\
\text { Regulation of } \\
\text { osmosensory genes. } \\
\text { Plant immunity signaling. } \\
\text { Binds to chromatin } \\
\text { (Jakoby et al. 2002; } \\
\text { Li et al. 2005; Loyter et al. } \\
\text { 2005; Pitzschke et al. } \\
\text { 2009; Tsugama et al. } \\
\text { 2014; Yi et al. 2006). }\end{array}$ & & & 3 & 4 & $\begin{array}{l}\text { Anchorage of the } \\
\text { T-complex to gene } \\
\text { promoters. } \\
\text { Preferential targeting } \\
\text { to VIP1 regulatory } \\
\text { targets. Preferential } \\
\text { targeting to } \\
\text { transcriptionally active } \\
\text { chromatin. }\end{array}$ \\
\hline VRE & $\begin{array}{l}\text { DNA binding motif } \\
\text { recognized by VIP1 } \\
\text { (Pitzschke et al. 2009). } \\
\text { Proposed to anchor the T- } \\
\text { complex to gene } \\
\text { promoters via VIP1. }\end{array}$ & $\begin{array}{l}\text { VIP1 response element. } \\
\text { Regulatory DNA motif } \\
\text { that occurs frequently in } \\
\text { stress responsive genes. } \\
\text { Binding site for VIP1 } \\
\text { (Pitzschke et al. 2009). }\end{array}$ & & & & 4 & $\begin{array}{l}\text { Anchorage of the } \\
\text { T-complex to gene } \\
\text { promoters containing } \\
\text { the VRE motif. } \\
\text { Preferential targeting } \\
\text { to VIP1 regulatory } \\
\text { targets. }\end{array}$ \\
\hline
\end{tabular}

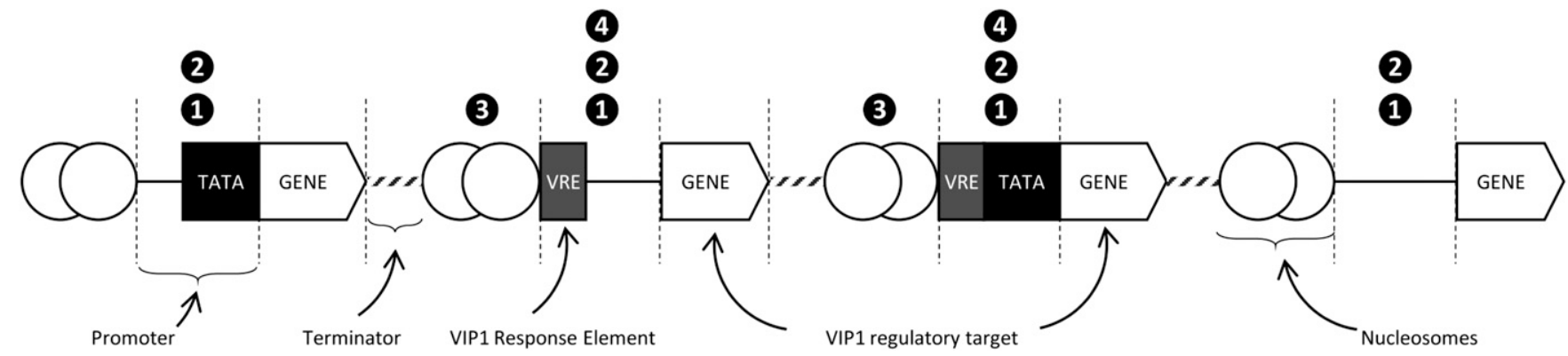

FIGURE 5

A proposed model for pathway-dependent targeting site for the T-DNA. Different genome compartments are schematically represented and indicated as promoter, terminator, gene, and nucleosomes. This model accounts for promoter composition based on the presence/absence of the TATA box and VIP1 response element (VRE) binding motifs. Nucleosomes account for intergenic regions serving as candidate chromatin binding sites for VIP1. Genes harboring the VRE motif are considered VIP regulatory targets. Pathway-dependent target sites are indicated by a number referring to pathways 1 to 4 (Table 1 and text provide details). Hypothetically, DNA damage occurring in any of these compartment and in the vicinity of the T-complex produces a potential site for T-DNA integration.

and (iii) formation of an homodimer that recognizes specific DNA motifs. A working hypothesis may be that the activation of transcription of stress responsive genes by VIP1 necessitates a transient DNA cleavage in their promoter regions and that transcription activation of target genes may also require an active DNA demethylation, a process which generates abasic sites (Ma et al. 2009). In such a scenario, the requirements favorable to the formation of topoisomerase II-mediated DSBs are fulfilled. A majority of DBSs will be efficiently repaired shortly after their formation, and probably in some cases, an illegitimate recombination through NHEJ pathway may lead to T-DNA integration in the promoters of these genes.

VIP1 in animals and fungi, the missing link. The role of VIP1 as a hub for protein interactions can only be proposed in plants since no VIP1 homolog was found so far in animals and fungi. One hypothesis is that the high level of "interactivity" that is characteristic of the role of VIP1 in plant-Agrobacterium interactions implies that VIP1 like proteins can only exist in plants as a result of a long coevolution between the host and the pathogen. Therefore, VIP1 homologs may not exist in nonhost organisms such as animals and fungi. Another hypothesis is that VIP1 absence is probably compensated by other virulence factors showing a certain level of functional redundancy. Of these, VirE3, VirD5, and VirD2 are plausible candidates that, taken together, can probably compensate for nuclear targeting, nuclear import, and chromatin targeting of the T-complex (Lacroix et al. 2005; Wang et al. 2014; Wolterink-van Loo et al. 2015). 
Another challenging aspect in mammals and fungi concerns the uncoating of the T-DNA complex which is mediated in plants by an interaction betweenVIP1 and one of the F-box proteins VirF or VBF. In budding yeast and the filamentous fungus Aspergillus awamori, a mutation in $v i r F$ does not hamper fungal transformation frequency (Bundock et al. 1995; Michielse et al. 2004), Mutations of virE2, the structural protein coating the T-strand, do not abolish transformation in A. awamori (Michielse et al. 2004). These results suggest that Agrobacterium-mediated transformation might rely on different host factors in filamentous fungi and probably in animal cells too. It also suggests that additional mechanisms of T-DNA integration are still to be discovered.

\section{AGROBACTERIUM'S BIOLOGY AS A TOOL FOR APPLIED RESEARCH}

T-DNA engineering without Agrobacterium. Most monocotyledonous plants are not natural host for A. tumefaciens (Binns and Thomashow 1988; Cleene 1985), suggesting that fundamental differences in the mechanisms of Agrobacterium transfection exist between monocotyledonous and dicotyledonous plants. Although several monocotyledonous plants including barley, maize, triticale, and wheat were successfully transformed (Hensel et al. 2009), it has been known for some time that monocots are difficult to transform via Agrobacterium, probably due to limited integration rates (Frame et al. 2002). It seems unlikely that T-DNA integration in monocots relies on completely different bacterial virulence factors and/or host proteins compared with dicots. Rather, it was reported that Agrobacterium elicits a series of plant defenses that can hamper Agrobacterium transfection (Ditt et al. 2006; Torres et al. 2006; Zipfel et al. 2006), which seems a more likely explanation to the difficulty of transformation in naturally resistant nonhost monocots. Thus, one possible solution is to bypass the requirement of using A. tumefaciens infection as a vehicle to transfer DNA to the host. In tobacco, reconstituted synthetic DNA-protein complexes, which mimic the T-complex, were successfully used to transform protoplasts (Ziemienowicz et al. 2001). Therefore, the possibility to bypass the need of an Agrobacterium infection to generate transformants is demonstrated. This technology was recently applied to monocots and the successful transformation of triticale plants by liposomes-mediated transfer of VirD2-ssDNA-RecA nano-complex to microspores has been reported (Ziemienowicz et al. 2012). It is unclear how such a complex can be anchored to the nucleosome, since previous studies showed that RecA transgenic tobacco plants cannot complement an Agrobacterium strain lacking the virE2 gene (Ziemienowicz et al. 2001). It is also unclear how the synthetic T-complex is processed in absence of bacterial virulence effectors such as VirE2 and VirD5, which suggests the existence of host factors which are capable of compensating for these factors. This promising result suggests that liposomes-mediated transfer of synthetic T-complex like nano-complexes is a conceivable alternative to bypass the limitations when relying on "natural" Agrobacterium transfection of nonhost plants, and thus, a valid alternative for the transformation of monocots including cereal crops.

Agrobacterium's effectors, an example of pathogen-derived resistance genes. Recent approaches involving molecular antiviral compounds to control viral diseases in plants have unexpectedly benefited from the extensive studies of Agrobacterium's transfection biology. Among Agrobacterium's virulence factors, VirE2 was identified as a potential antiviral protein against geminiviruses, a large family of DNA viruses infecting a wide range of crops (Resmi et al. 2015; Sunitha et al. 2011). In these studies, the ability of VirE2 to bind and coat single-stranded DNA revealed to be effective against the Sri Lanka cassava mosaic virus (SLCMV) and the Mungbean yellow mosaic virus (MYMV) (Resmi et al. 2015; Sunitha et al. 2011). These are unique examples where a plant pathogen-derived effector protein provides a certain level of resistance against another plant disease. Whether this kind of interactions is common in nature, or can be reproduced in field conditions, is still to be investigated. Nevertheless, this discovery opens new perspectives for pathogen-informed strategies to improve disease resistance in the future.

Agrobacterium as a model for pathogen-informed S-gene breeding. Agrobacterium has been a remarkable tool for genetic engineering in plant and nonplant organisms. Agrobacterium's transfection is also by far one of the most dissected disease mechanisms in plant pathology. This review illustrates advances in our understanding of the molecular and biochemical processes underlying successful disease development in Agrobacterium transfection with unparalleled work across three kingdoms of life. Already, over 40 plant proteins were described as "hijacked" by Agrobacterium and/or contributing to infection (Gelvin 2010). These plant targets are typical examples of susceptibility genes (S-genes) that promote pathogen proliferation and disease development (Gawehns et al. 2013; Pavan et al. 2010). Therefore, Agrobacterium's Vir effector genes and their plant targets could serve as a model system for tackling pathogen-informed S-gene breeding for plant innate immunity (Gawehns et al. 2013; Vleeshouwers and Oliver 2014).

\section{LITERATURE CITED}

Abu-Arish, A., Frenkiel-Krispin, D., Fricke, T., Tzfira, T., Citovsky, V., Wolf, S. G., and Elbaum, M. 2004. Three-dimensional reconstruction of Agrobacterium VirE2 protein with single-stranded DNA. J. Biol. Chem. 279: 25359-25363.

Acilan, C., Potter, D. M., and Saunders, W. S. 2007. DNA repair pathways involved in anaphase bridge formation. Genes Chromosomes Cancer 46:522-531.

Akiyoshi, D. E., Klee, H., Amasino, R. M., Nester, E. W., and Gordon, M. P. 1984. T-DNA of Agrobacterium tumefaciens encodes an enzyme of cytokinin biosynthesis. Proc. Natl. Acad. Sci. USA 81:5994-5998.

Alonso, J. M., Stepanova, A. N., Leisse, T. J., Kim, C. J., Chen, H., Shinn, P., Stevenson, D. K., Zimmerman, J., Barajas, P., Cheuk, R., Gadrinab, C., Heller, C., Jeske, A., Koesema, E., Meyers, C. C., Parker, H., Prednis, L., Ansari, Y., Choy, N., Deen, H., Geralt, M., Hazari, N., Hom, E., Karnes, M., Mulholland, C., Ndubaku, R., Schmidt, I., Guzman, P., Aguilar-Henonin, L., Schmid, M., Weigel, D., Carter, D. E., Marchand, T., Risseeuw, E., Brogden, D., Zeko, A., Crosby, W. L., Berry, C. C., and Ecker, J. R. 2003. Genome-wide insertional mutagenesis of Arabidopsis thaliana. Science 301:653-657.

Anand, A., Krichevsky, A., Schornack, S., Lahaye, T., Tzfira, T., Tanga, Y., Citovsky, V., and Mysore, K. S. 2007b. Arabidopsis VirE2 interacting protein2 is required for Agrobacterium T-DNA integration in plants. Plant Cell 19:1695-1708.

Anand, A., Vaghchhipawala, Z., Ryu, C. M., Kang, L., Wang, K., del-Pozo, O., Martin, G. B., and Mysore, K. S. 2007a. Identification and characterization of plant genes involved in Agrobacterium-mediated plant transformation by virus-induced gene silencing. Mol. Plant-Microbe Interact. 20:41-52.

Avivi, Y., Morad, V., Ben-Meir, H., Zhao, J., Kashkush, K., Tzfira, T., Citovsky, V., and Grafi, G. 2004. Reorganization of specific chromosomal domains and activation of silent genes in plant cells acquiring pluripotentiality. Dev. Dyn. 230:12-22.

Bako, L., Umeda, M., Tiburcio, A. F., Schell, J., and Koncz, C. 2003. The VirD2 pilot protein of Agrobacterium-transferred DNA interacts with the TATA box-binding protein and a nuclear protein kinase in plants. Proc. Natl. Acad. Sci. USA 100:10108-10113.

Balajee, A. S., and Bohr, V. A. 2000. Genomic heterogeneity of nucleotide excision repair. Gene 250:15-30.

Barker, R. F., Idler, K. B., Thompson, D. V., and Kemp, J. D. 1983. Nucleotide sequence of the T-DNA region from the Agrobacterium tumefaciens octopine Ti-plasmid pTi15955. Plant Mol. Biol. 2:335-350.

Barzel, A., and Kupiec, M. 2008. Finding a match: How do homologous sequences get together for recombination? Nat. Rev. Genet. 9:27-37.

Basehoar, A. D., Zanton, S. J., and Pugh, B. F. 2004. Identification and distinct regulation of yeast TATA box-containing genes. Cell 116:699-709.

Baur, M., Potrykus, I., and Paszkowski, J. 1990. Intermolecular homologous recombination in plants. Mol. Cell. Biol. 10:492-500.

Berchowitz, L. E., Hanlon, S. E., Lieb, J. D., and Copenhaver, G. P. 2009. A positive but complex association between meiotic double-strand break hotspots and open chromatin in Saccharomyces cerevisiae. Genome Res. 19:2245-2257. 
Bernstein, K. A., and Rothstein, R. 2009. At loose ends: Resecting a doublestrand break. Cell 137:807-810.

Bharat, T. A., Zbaida, D., Eisenstein, M., Frankenstein, Z., Mehlman, T., Weiner, L., Sorzano, C. O., Barak, Y., Albeck, S., Briggs, J. A., Wolf, S. G., and Elbaum, M. 2013. Variable internal flexibility characterizes the helical capsid formed by Agrobacterium VirE2 protein on single-stranded DNA. Structure 21:1158-1167.

Bhattacharya, A., Sood, P., and Citovsky, V. 2010. The roles of plant phenolics in defence and communication during Agrobacterium and Rhizobium infection. Mol. Plant Pathol. 11:705-719.

Binns, A. N., and Thomashow, M. F. 1988. Cell biology of Agrobacterium infection and transformation of plants. Annu. Rev. Microbiol. 42:575-606.

Blaise, F., Remy, E., Meyer, M., Zhou, L., Narcy, J. P., Roux, J., Balesdent, M., and Rouxel, T. 2007. A critical assessment of Agrobacterium tumefaciens-mediated transformation as a tool for pathogenicity gene discovery in the phytopathogenic fungus Leptosphaeria maculans. Fungal Genet. Biol. 44:123-138.

Blitzblau, H. G., Bell, G. W., Rodriguez, J., Bell, S. P., and Hochwagen, A. 2007. Mapping of meiotic single-stranded DNA reveals double-strandedbreak hotspots near centromeres and telomeres. Curr. Biol. 17:2003-2012.

Bosco, E. E., Mayhew, C. N., Hennigan, R. F., Sage, J., Jacks, T., and Knudsen, E. S. 2004. RB signalling prevents replication-dependent DNA double-strand breaks following genotoxic insult. Nucleic Acids Res. 32: 25-34.

Bourras, S., Meyer, M., Grandaubert, J., Lapalu, N., Fudal, I., Linglin, J., Ollivier, B., Blaise, F., Balesdent, M. H., and Rouxel, T. 2012. Incidence of genome structure, DNA asymmetry, and cell physiology on T-DNA integration in chromosomes of the phytopathogenic fungus Leptosphaeria maculans. G3 (Bethesda) 2:891-904.

Braun, A. C. 1952. The crown-gall disease. Ann. N.Y. Acad. Sci. 54: 1153-1161.

Broothaerts, W., Mitchell, H. J., Weir, B., Kaines, S., Smith, L. M., Yang, W., Mayer, J. E., Roa-Rodríguez, C., and Jefferson, R. A. 2005. Gene transfer to plants by diverse species of bacteria. Nature 433:629-633.

Brunaud, V., Balzergue, S., Dubreucq, B., Aubourg, S., Samson, F., Chauvin, S., Bechtold, N., Cruaud, C., DeRose, R., Pelletier, G., Lepiniec, L., Caboche, M., and Lecharny, A. 2002. T-DNA integration into the Arabidopsis genome depends on sequences of pre-insertion sites. EMBO Rep. 12: 1152-1157.

Buchmann, I., Marner, F. J., Schröder, G., Waffenschmidt, S., and Schröder, J. 1985. Tumour genes in plants: T-DNA encoded cytokinin biosynthesis. EMBO J. 4:853-859.

Buhler, C., Borde, V., and Lichten, M. 2007. Mapping meiotic single-strand DNA reveals a new landscape of DNA double-strand breaks in Saccharomyces cerevisiae. PLoS Biol. 5:e324.

Bundock, P., den Dulk-Ras, A., Beijersbergen, A., and Hooykaas, P. J. J. 1995. Trans-kingdom T-DNA transfer from Agrobacterium tumefaciens to Saccharomyces cerevisiae. EMBO J. 14:3206-3214.

Cangelosi, G. A., Ankenbauer, R. G., and Nester, E. W. 1990. Sugars induce the Agrobacterium virulence genes through a periplasmic binding protein and a transmembrane signal protein. Proc. Natl. Acad. Sci. USA 87: 6708-6712.

Chambers, A. L., and Downs, J. A. 2007. The contribution of the budding yeast histone H2A C-terminal tail to DNA-damage responses. Biochem. Soc. Trans. 35:1519-1524.

Chilton, M.-D., and Que, Q. 2003. Targeted integration of T-DNA into the tobacco genome at double-stranded breaks: New insights on the mechanism of T-DNA integration. Plant Physiol. 133:956-965.

Choi, J., Park, J., Jeon, J., Chi, M.-H., Goh, J., Yoo, S.-Y., Park, J., Jung, K., Kim, H., Park, S.-Y., Rho, H.-S., Kim, S., Kim, B. R., Han, S.-S., Kang, S., and Lee, Y.-H. 2007. Genome-wide analysis of T-DNA integration into the chromosomes of Magnaporthe oryzae. Mol. Microbiol. 66:371-382.

Christie, P. J., Atmakuri, K., Krishnamoorthy, V., Jakubowski, S., and Cascales, E. 2005. Biogenesis, architecture, and function of bacterial type IV secretion systems. Annu. Rev. Microbiol. 59:451-485.

Citovsky, V., Guralnick, B., Simon, M. N., and Wall, J. S. 1997. The molecular structure of Agrobacterium VirE2-single stranded DNA complexes involved in nuclear import. J. Mol. Biol. 271:718-727.

Citovsky, V., Kozlovsky, S. V., Lacroix, B., Zaltsman, A., Dafny-Yelin, M., Vyas, S., Tovkach, A., and Tzfira, T. 2007. Biological systems of the host cell involved in Agrobacterium infection. Cell. Microbiol. 9:9-20.

Clark, K. A., and Krysan, P. J. 2010. Chromosomal translocations are a common phenomenon in Arabidopsis thaliana T-DNA insertion lines. Plant J. 64:990-1001.

Cleene, M. 1985. The susceptibility of monocotyledonous to Agrobacterium tumefaciens. J. Phytopathol. 113:81-89.

Coin, F., Oksenych, V., Mocquet, V., Groh, S., Blattner, C., and Egly, J. M. 2008. Nucleotide excision repair driven by the dissociation of CAK from TFIIH. Mol. Cell 31:9-20.
Collart, M. A. 2003. Global control of gene expression in yeast by the Ccr4Not complex. Gene 313:1-16.

Collart, M. A., and Timmers, H. T. 2004. The eukaryotic Ccr4-Not complex: A regulatory platform integrating mRNA metabolism with cellular signaling pathways? Prog. Nucleic Acid Res. Mol. Biol. 77:289-322.

Core, L. J., Waterfall, J. J., and Lis, J. T. 2008. Nascent RNA sequencing reveals widespread pausing and divergent initiation at human promoters. Science 322:1845-1848.

Crane, Y. M., and Gelvin, S. 2007. RNAi-mediated gene silencing reveals involvement of Arabidopsis chromatin-related genes in Agrobacteriummediated root transformation. Proc. Natl. Acad. Sci. USA 104:15156-15161.

de Groot, M. J., Bundock, P., Hooykaas, P. J., and Beijersbergen, A. G. 1998. Agrobacterium tumefaciens-mediated transformation of filamentous fungi. Nat. Biotechnol. 16:839-842.

del Pozo, J. C., and Estelle, M. 2000. F-box proteins and protein degradation: An emerging theme in cellular regulation. Plant Mol. Biol. 44:123-128.

Dessaux, Y., Petit, A., and Tempe, J. 1993. Chemistry and biochemistry of opines, chemical mediators of parasitism. Phytochemistry 34:31-38.

Ditt, R. F., Kerr, K. F., de Figueiredo, P., Delrow, J., Comai, L., and Nester, E. W. 2006. The Arabidopsis thaliana transcriptome in response to Agrobacterium tumefaciens. Mol. Plant-Microbe Interact. 19:665-681.

Dudas, A., and Chovanec, M. 2004. DNA double-strand break repair by homologous recombination. Mutat. Res. 556:131-167.

Dvir, A., Conaway, J. W., and Conaway, R. C. 2001. Mechanism of transcription initiation and promoter escape by RNA polymerase II. Curr. Opin. Genet. Dev. 11:209-214.

Eckardt, N. A. 2004. Host proteins guide Agrobacterium-mediated plant transformation. Plant Cell 16:2837-2839.

Escobar, M. A., and Dandekar, A. M. 2003. Agrobacterium tumefaciens as an agent of disease. Trends Plant Sci. 8:380-386.

Frame, B. R., Shou, H., Chikwamba, R. K., Zhang, Z., Xiang, C., Fonger, T. M., Pegg, S. E., Li, B., Nettleton, D. S., Pei, D., and Wang, K. 2002. Agrobacterium tumefaciens-mediated transformation of maize embryos using a standard binary vector system. Plant Physiol. 129:13-22.

Frank-Vaillant, M., and Marcand, S. 2002. Transient stability of DNA ends allows nonhomologous end joining to precede homologous recombination. Mol. Cell 10:1189-1199.

Fronzes, R., Christie, P. J., and Waksman, G. 2009. The structural biology of type IV secretion systems. Nat. Rev. Microbiol. 7:703-714.

Fujimori, S., Washio, T., and Tomita, M. 2005. GC-compositional strand bias around transcription start sites in plants and fungi. BMC Genomics 6:26.

Garcia-Rodriguez, F. M., Schrammeijer, B., and Hooykaas, P. J. J. 2006. The Agrobacterium VirE3 effector protein: A potential plant transcriptional activator. Nucleic Acids Res. 34:6496-6504.

Gasior, S. L., Wakeman, T. P., Xu, B., and Deininger, P. L. 2006. The human LINE-1 retrotransposon creates DNA double-strand breaks. J. Mol. Biol. 357:1383-1393.

Gawehns, F., Cornelissen, B. J., and Takken, F. L. 2013. The potential of effector-target genes in breeding for plant innate immunity. Microbiol. Biotechnol. 6:223-229.

Gelvin, S. B. 2010. Finding a way to the nucleus. Curr. Opin. Microbiol. 13:53-58.

Guenther, M. G., Levine, S. S., Boyer, L. A., Jaenisch, R., and Young, R. A. 2007. A chromatin landmark and transcription initiation at most promoters in human cells. Cell 13:77-88.

Guyon, P., Chilton, M. D., Petit, A., and Tempé, J. 1980. Agropine in "null-type" crown gall tumors: Evidence for generality of the opine concept. Proc. Natl. Acad. Sci. USA 77:2693-2697.

Haffner, M. C., Aryee, M. J., Toubaji, A., Esopi, D. M., Albadine, R., Gurel, B., Isaacs, W. B., Bova, G. S., Liu, W., Xu, J., Meeker, A. K., Netto, G., De Marzo, A. M., Nelson, W. G., and Yegnasubramanian, S. 2010. Androgen-induced TOP $2 \beta$-mediated double-strand breaks and prostate cancer gene rearrangements. Nat. Genet. 42:668-675.

Hampsey, M. 1998. Molecular genetics of the RNA polymerase II general transcription machinery. Microbiol. Mol. Biol. Rev. 62:465-503.

Hanada, K., Budzowska, M., Davies, S. L., van Drunen, E., Onizawa, H., Beverloo, H. B., Maas, A., Essers, J., Hickson, I. D., and Kanaar, R. 2007. The structure-specific endonuclease Mus81 contributes to replication restart by generating double-strand breaks. Nat. Struct. Mol. Biol. 14:1096-1104.

Hanawalt, P. C., and Spivak, G. 2008. Transcription-coupled DNA repair: Two decades of progress and surprises. Nat. Rev. Mol. Cell Biol. 9:958-970.

Harper, J. V., Anderson, J. A., and O'Neill, P. 2010. Radiation induced DNA DSBs: Contribution from stalled replication forks? DNA Repair (Amst.) 9: 907-913.

Hensel, G., Kastner, C., Oleszczuk, S., Riechen, J., and Kumlehn, J. 2009. Agrobacterium-mediated gene transfer to cereal crop plants: Current protocols for barley, wheat, triticale, and maize. Int. J. Plant Genomics 2009:835608.

Ho, M. S., Ou, C., Chan, Y. R., Chien, C. T., and Pi, H. 2008. The utility F-box for protein destruction Cell. Mol. Life Sci. 65:1977-2000. 
Hooykaas, P. J., Klapwijk, P. M., Nuti, M. P., Schilperoort, R. A., and Rorsch, A. 1977. Transfer of the Agrobacterium tumefaciens Ti plasmid to avirulent agrobacteria and to explanta. J. Gen. Microbiol. 98:477-484.

Hua, S. B., Qiu, M., Chan, E., Zhu, L., and Luo, Y. 1997. Minimum length of sequence homology required for in vivo cloning by homologous recombination in yeast. Plasmid 38:91-96.

Jackson, S. P. 2002. Sensing and repairing DNA double-strand breaks. Carcinogenesis 23:687-696.

Jakoby, M., Weisshaar, B., Dröge-Laser, W., Vicente-Carbajosa, J., Tiedemann, J., Kroj, T., Parcy, F., and bZIP Research Group. 2002. bZIP transcription factors in Arabidopsis. Trends Plant Sci. 7:106-111.

Ju, B.-G., Lunyak, V. V., Perissi, V., Garcia-Bassets, I., Rose, D. W., Glass, C. K., and Rosenfeld, M. G. 2006. A topoisomerase II $\beta$-mediated dsDNA break required for regulated transcription. Science 321:1798-1802.

Keeney, S., and Neale, M. J. 2006. Initiation of meiotic recombination by formation of DNA double-strand breaks: Mechanism and regulation. Biochem. Soc. Trans. 34:523-525.

Kim, K. S., and Farrand, S. K. 1996. Ti plasmid-encoded genes responsible for catabolism of the crown gall opine mannopine by Agrobacterium tumefaciens are homologs of the T-region genes responsible for synthesis of this opine by the plant tumor. J. Bacteriol. 178:3275-3284.

Kim, S.-I., Veena, and Gelvin, S. B. 2007. Genome-wide analysis of Agrobacterium T-DNA integration sites in the Arabidopsis genome generated under non-selective conditions. Plant J. 51:779-791.

Kim, T.-K., Ebright, R. H., and Reinberg, D. 2000. Mechanism of ATP-dependent promoter melting by transcription factor IIH. Science 288:1418-1421.

Klar, A. J., Bonaduce, M. J., and Cafferkey, R. 1991. The mechanism of fission yeast mating type interconversion: Seal/replicate/cleave model of replication across the double-stranded break site of mat1. Genetics 127: 489-496.

Komari, T., Halperin, W., and Nester, E. W. 1986. Physical and functional map of supervirulent Agrobacterium tumefaciens tumor-inducing plasmid pTiBo542. J. Bacteriol. 166:88-94.

Kunik, T., Tzfira, T., Kapulnik, Y., Gafni, Y., Dingwall, C., and Citovsky, V. 2001. Genetic transformation of HeLa cells by Agrobacterium. Proc. Natl. Acad. Sci. USA 98:1871-1876.

Lacroix, B., and Citovsky, V. 2013a. Characterization of VIP1 activity as a transcriptional regulator in vitro and in planta. Sci. Rep. 3:2440.

Lacroix, B., and Citovsky, V. 2013b. A mutation in negative regulator of basal resistance WRKY17 of Arabidopsis increases susceptibility to Agrobacteriummediated genetic transformation. F1000 Res. 2:33.

Lacroix, B., Loyter, A., and Citovsky, V. 2008. Association of the Agrobacterium T-DNA-protein complex with plant nucleosomes. Proc. Natl. Acad. Sci. USA 105:15429-15434.

Lacroix, B., Vaidya, M., Tzfira, T., and Citovsky, V. 2005. The VirE3 protein of Agrobacterium mimics a host cell function required for plant genetic transformation. EMBO J. 24:428-437.

Li, J., Krichevsky, A., Vaidya, M., Tzfira, T., and Citovsky, V. 2005. Uncoupling of the functions of the Arabidopsis VIP1 protein in transient and stable plant genetic transformation by Agrobacterium. Proc. Natl. Acad. Sci. USA 102:5733-5738.

Li, L., Jia, Y., Hou, Q., Charles, T. C., Nester, E. W., and Pan, S. Q. 2002. A global $\mathrm{pH}$ sensor: Agrobacterium sensor protein ChvG regulates acidinducible genes on its two chromosomes and Ti plasmid. Proc. Natl. Acad. Sci. USA 99:12369-12374.

Li, T.-K., Chen, A. Y., Yu, C., Mao, Y., Wang, H., and Liu, L. F. 1999. Activation of topoisomerase II-mediated excision of chromosomal DNA loops during oxidative stress. Genes Dev. 13:1553-1560.

Limoli, C. L., Giedzinski, E., Bonner, W. M., and Cleaver, J. E. 2002. UVinduced replication arrest in the xeroderma pigmentosum variant leads to DNA double-strand breaks, gamma-H2AX formation, and Mre11 relocalization. Proc. Natl. Acad. Sci. USA 99:233-238.

Liu, Y., Kong, X., Pan, J., and Li, D. 2010. VIP1: Linking Agrobacteriummediated transformation to plant immunity? Plant Cell Rep. 29:805-812.

Loyter, A., Rosenbluh, J., Zakai, N., Li, J., Kozlovsky, S. V., Tzfira, T., and Citovsky, V. 2005. The plant VirE2 interacting protein 1. A molecular link between the Agrobacterium T-complex and the host cell chromatin? Plant Physiol. 138:1318-1321.

Ma, D. K., Guo, J. U., Ming, G. L., and Song, H. 2009. DNA excision repair proteins and Gadd45 as molecular players for active DNA demethylation. Cell Cycle 8:1526-1531.

Ma, J. L., Kim, E. M., Haber, J. E., and Lee, S. E. 2003. Yeast Mre11 and Rad1 proteins define a Ku-independent mechanism to repair double-strand breaks lacking overlapping end sequences. Mol. Cell. Biol. 23:8820-8828.

Maes, M., Amit, E., Danieli, T., Lebendiker, M., Loyter, A., and Friedler, A. 2014. The disordered region of Arabidopsis VIP1 binds the Agrobacterium VirE2 protein outside its DNA-binding site. Protein Eng. Des. Sel. 27: 439-446.
Magori, S., and Citovsky, V. 2011. Agrobacterium counteracts host-induced degradation of its effector F-box protein. Sci. Signal. 4:ra69.

Majhi, B. B., Shah, J. M., and Veluthambi, K. 2014. A novel T-DNA integration in rice involving two interchromosomal translocations. Plant Cell Rep. 33:929-44.

Mandraju, R., Chekuri, A., Bhastar, C., Duning, K., Kremerskothen, J., and Kondapi, A. K. 2011. Topoisomerase II $\beta$ associates with Ku70 and PARP-1 during double strand break repair of DNA in neurons. Arch. Biochem. Biophys. 516:128-137.

McVey, M., and Lee, S. E. 2008. MMEJ repair of double-strand breaks director's cut: Deleted sequences and alternative endings. Trends Genet. 24:529-538.

Metivier, R., Gallais, R., Tiffoche, C., Le Péron, C., Jurkowska, R. Z., Carmouche, R. P., Ibberson, D., Barath, P., Demay, F., Reid, G., Benes, V., Jeltsch, A., Gannon, F., and Salbert, G. 2008. Cyclical DNA methylation of a transcriptionally active promoter. Nature 452:45-51.

Michielse, C. B., Hooykaas, P. J., van den Hondel, C. A., and Ram, A. F. 2005. Agrobacterium-mediated transformation as a tool for functional genomics in fungi. Curr. Genet. 48:1-17.

Michielse, C. B., Ram, A. F., Hooykaas, P. J., and van den Hondel, C. A. 2004. Agrobacterium-mediated transformation of Aspergillus awamori in the absence of full-length VirD2, VirC2, or VirE2 leads to insertion of aberrant T-DNA structures. J. Bacteriol. 186:2038-2045.

Moore, L. W., Chilton, W. S., and Canfield, M. L. 1997. Diversity of opines and opine-catabolizing bacteria isolated from naturally occurring crown gall tumors. Appl. Environ. Microbiol. 63:201-207.

Mosley, A. L., Pattenden, S. G., Carey, M., Venkatesh, S., Gilmore, J. M., Florens, L., Workman, J. L., and Washburn, M. P. 2009. Rtr1 is a CTD phosphatase that regulates RNA polymerase II during the transition from serine 5 to serine 2 phosphorylation. Mol. Cell 34:168-178.

Mysore, K. S., Nam, J., and Gelvin, S. B. 2000. An Arabidopsis histone H2A mutant is deficient in Agrobacterium T-DNA integration. Proc. Natl. Acad. Sci. USA 97:948-953.

Nacry, P., Camilleri, C., Courtial, B., Caboche, M., and Bouchez, D. 1998. Major chromosomal rearrangements induced by T-DNA transformation in Arabidopsis. Genetics 149:641-50.

Palanichelvam, K., and Veluthambi, K. 1996. Octopine- and nopaline-inducible proteins in Agrobacterium tumefaciens are also induced by arginine. Curr. Microbiol. 33:156-162.

Pavan, S., Jacobsen, E., Visser, R. G., and Bai, Y. 2010. Loss of susceptibility as a novel breeding strategy for durable and broad-spectrum resistance. Mol. Breed. 25:1-12.

Pena-Diaz, J., and Jiricny, J. 2012. Mammalian mismatch repair: Error-free or error-prone. Trends Biochem. Sci. 37:206-214.

Piers, K. L., Heath, J. D., Liang, X., Stephens, K. M., and Nester, E. W. 1996. Agrobacterium tumefaciens-mediated transformation of yeast. Proc. Natl. Acad. Sci. USA 93:1613-1618.

Pitzschke, A., Djamei, A., Teige, M., and Hirt, H. 2009. VIP1 response elements mediate mitogen-activated protein kinase 3-induced stress gene expression. Proc. Natl. Acad. Sci. USA 106:18414-18419.

Pitzschke, A., and Hirt, H. 2010. New insights into an old story: Agrobacteriuminduced tumour formation in plants by plant transformation. EMBO J. 29: 1021-1032.

Resmi, T. R., Hohn, T., Hohn, B., and Veluthambi, K. 2015. The Agrobacterium tumefaciens Ti plasmid virulence gene virE2 reduces Sri Lankan cassava mosaic virus infection in transgenic Nicotiana benthamiana plants. Viruses 7:2641-2653.

Ricchetti, M., Dujon, B., and Fairhead, C. 2003. Distance from the chromosome end determines the efficiency of double strand break repair in subtelomeres of haploid yeast. J. Mol. Biol. 328:847-862.

Rubnitz, J., and Subramani, S. 1984. The minimum amount of homology required for homologous recombination in mammalian cells. Mol. Cell. Biol. 4:2253-2258.

Schneeberger, R. G., Zhang, K., Tatarinova, T., Troukhan, M., Kwok, S. F., Drais, J., Klinger, K., Orejudos, F., Macy, K., Bhakta, A., Burns, J., Subramanian, G., Donson, J., Flavell, R., and Feldmann, K. A. 2005. Agrobacterium T-DNA integration in Arabidopsis is correlated with DNA sequence compositions that occur frequently in gene promoter regions. Funct. Integr. Genomics 5:240-253.

Schrammeijer, B., Risseeuw, E., Pansegrau, W., Regensburg-Tuïnk, T. J. G., Crosby, W. L., and Hooykaas, P. J. J. 2001. Interaction of the virulence protein VirF of Agrobacterium tumefaciens with plant homologs of the yeast Skp1 protein. Curr. Biol. 11:258-262.

Shi, Y., Lee, L. Y., and Gelvin, S. B. 2014. Is VIP1 important for Agrobacteriummediated transformation? Plant J. 79:848-860.

Shrivastav, M., De Haro, L. P., and Nickoloff, J. A. 2008. Regulation of DNA double-strand break repair pathway choice. Cell Res. 18:137-147.

Smale, S. T., and Kadonaga, J. T. 2003. The RNA polymerase II core promoter. Annu. Rev. Biochem. 72:449-479. 
Somers, D. E., and Fujiwara, S. 2009. Thinking outside the F-box: Novel ligands for novel receptors. Trends Plant Sci. 14:206-213.

Soyer, J. L., El Ghalid, M., Glaser, N., Ollivier, B., Linglin, J., Grandaubert, J., Balesdent, M.-H., Connolly, L. R., Freitag, M., Rouxel, T., and Fudal, I. 2014. Epigenetic control of effector gene expression in the plant pathogenic fungus Leptosphaeria maculans. PLoS Genet. 10:e1004227.

Stachel, S. E., Messens, E., van Montagu, M., and Zambryski, P. 1985. Identification of the signal molecules produced by wounded plant cells that activate T-DNA transfer in Agrobacterium tumefaciens. Nature 318: 624-629.

Stachel, S. E., and Nester, E. W. 1986. The genetic and transcriptional organization of the vir region of the A6 plasmid of Agrobacterium tumefaciens. EMBO J. 5:1445-1454.

Storz, G., Altuvia, S., and Wassarman, K. M. 2005. An abundance of RNA regulators. Annu. Rev. Biochem. 74:199-217.

Stratmann, J. W., and Gusmaroli, G. 2012. Many jobs for one good cop-The COP9 signalosome guards development and defense. Plant Sci. 186:50-64.

Sunitha, S., Marian, D., Hohn, B., and Veluthambi, K. 2011. Antibegomoviral activity of the agrobacterial virulence protein VirE2. Virus Genes 43: 445-453.

Suzuki, K., Hattori, Y., Uraji, M., Ohta, N., Iwata, K., Murata, K., Kato, A., and Yoshida, K. 2000. Complete nucleotide sequence of a plant tumorinducing Ti plasmid. Gene 242:331-336.

Svejstrup, J. Q. 2002. Transcription repair coupling factor: A very pushy enzyme. Mol. Cell 9:1151-1152.

Svejstrup, J. Q., Wang, Z., Feaver, W. J., Wu, X., Bushnell, D. A., Donahue, T. F., Friedberg, E. C., and Kornberg, R. D. 1995. Different forms of TFIIH for transcription and DNA repair: Holo-TFIIH and a nucleotide excision repairosome. Cell 80:21-28.

Szabados, L., Kovács, I., Oberschall, A., Ábrahám, E., Kerekes, I., Zsigmond, L., Nagy, R., Alvarado, M., Krasovskaja, I., Gál, M., Berente, A., Rédei, G. P., Ben-Haim, A., and Koncz, C. 2002. Distribution of 1000 sequenced T-DNA tags in the Arabidopsis genome. Plant J. 32:233-242.

Tatarinova, T., Brover, V., Troukhan, M., and Alexandrov, N. 2003. Skew in CG content near the transcription start site in Arabidopsis thaliana. Bioinformatics 19:313-314.

Tenea, G. N., Spantzel, J., Lee, L.-Y., Zhu, Y., Lin, K., Johnson, S. J., and Gelvin, S. B. 2009. Overexpression of several Arabidopsis histone genes increases Agrobacterium-mediated transformation and transgene expression in plants. Plant Cell 21:3350-3367.

Teyssier-Cuvelle, S., Oger, P., Mougel, C., Groud, K., Farrand, S. K., and Nesme, X. 2004. A highly selectable and highly transferable Ti plasmid to study conjugal host range and Ti plasmid dissemination in complex ecosystems. Microbiol. Ecol. 48:10-18.

Tinland, B. 1996. The integration of T-DNA into plant genomes. Trends Plant Sci. 1:178-184.

Torres, M. A., Jones, J. D., and Dangl, J. L. 2006. Reactive oxygen species signaling in response to pathogens. Plant Physiol. 141:373-378.

Tsugama, D., Liu, S., and Takano, T. 2012. A bZIP protein, VIP1, is a regulator of osmosensory signaling in Arabidopsis. Plant Physiol. 159:144-155.

Tsugama, D., Liu, S., and Takano, T. 2014. Analysis of functions of VIP1 and its close homologs in osmosensory responses of Arabidopsis thaliana. PLoS One 9:e103930.

Tzfira, T., Li, J., Lacroix, B., and Citovsky, V. 2004a. Agrobacterium T-DNA integration: Molecules and models. Trends Genet. 20:375-383.

Tzfira, T., Vaidya, M., and Citovsky, V. 2001. VIP1, an Arabidopsis protein that interacts with Agrobacterium VirE2, is involved in VirE2 nuclear import and Agrobacterium infectivity. EMBO J. 20:3596-3607.

Tzfira, T., Vaidya, M., and Citovsky, V. 2002. Increasing plant susceptibility to Agrobacterium infection by overexpression of the Arabidopsis nuclear protein VIP1. Proc. Natl. Acad. Sci. USA 99:10435-10440.

Tzfira, T., Vaidya, M., and Citovsky, V. 2004b. Involvement of targeted proteolysis in plant genetic transformation by Agrobacterium. Nature 431:87-92.

Umeda, M., Shimotohno, A., and Yamaguchi, M. 2005. Control of cell division and transcription by cyclin-dependent kinase-activating kinases in plants. Plant Cell Physiol. 46:1437-1442.
Venters, B. J., and Pugh, B. F. 2009. A canonical promoter organization of the transcription machinery and its regulators in the Saccharomyces genome. Genome Res. 19:360-371.

Vleeshouwers, V. G., and Oliver, R. P. 2014. Effectors as tools in disease resistance breeding against biotrophic, hemibiotrophic, and necrotrophic plant pathogens. Mol. Plant-Microbe Interact. 27:196-206.

Volokhina, I. V., Gusev, Y. S., Mazilov, S. I., and Chumakov, M. I. 2011. Supramolecular complexes of the Agrobacterium tumefaciens virulence protein VirE2. Biochemistry 76:1270-1275

Wang, Y., Peng, W., Zhou, X., Huang, F., Shao, L., and Luo, M. 2014. The putative Agrobacterium transcriptional activator-like virulence protein VirD5 may target T-complex to prevent the degradation of coat proteins in the plant cell nucleus. New Phytol. 203:1266-1281.

Wilusz, J. E., Sunwoo, H., and Spector, D. L. 2009. Long noncoding RNAs: functional surprises from the RNA world. Genes Dev. 23:1494-1504.

Winans, S. C. 1992. Two-way chemical signaling in Agrobacterium-plant interactions. Microbiol. Rev. 56:12-31.

Wolterink-van Loo, S., Escamilla Ayala, A. A., Hooykaas, P. J., and van Heusden, G. P. 2015. Interaction of the Agrobacterium tumefaciens virulence protein VirD2 with histones. Microbiology 161:401-410.

Yamaguchi, M., Umeda, M., and Uchimiya, H. 1998. A rice homolog of CDK7/MO15 phosphorylates both cyclin-dependent protein kinases and the carboxy-terminal domain of RNA polymerase II. Plant J. 16: 613-619.

Yi, H., Mysore, K. S., and Gelvin, S. B. 2002. Expression of the Arabidopsis histone H2A-1 gene correlates with susceptibility to Agrobacterium transformation. Plant J. 32:285-298.

Yi, H., Sardesai, N., Fujinuma, T., Chan C.-W., Veena, and Gelvin, S. B. 2006. Constitutive expression exposes functional redundancy between the Arabidopsis histone $\mathrm{H} 2 \mathrm{~A}$ gene HTA1 and other H2A gene family members. Plant Cell 18:1575-1589.

Zaltsman, A., Krichevsky, A., Loyster, A., and Citovsky, V. 2010. Agrobacterium induces expression of a host F-box protein required for tumorigenicity. Cell Host Microbe 7:197-209.

Zeitlinger, J., Stark, A., Kellis, M., Hong, J. W., Nechaev, S., Adelman, K., Levine, M., and Young, R. A. 2007. RNA polymerase stalling at developmental control genes in the Drosophila melanogaster embryo. Nat. Genet. 39:1512-1516.

Zhang, J., Guo, D., Chang, Y., You, C., Li, X., Dai, X., Weng, Q., Zhang, J., Chen, G., Li, X., Liu, H., Han, B., Zhang, Q., and Wu, C. 2007. Nonrandom distribution of T-DNA insertions at various levels of the genome hierarchy as revealed by analyzing 13804 T-DNA flanking sequences from an enhancer-trap mutant library. Plant J. 49:947-959.

Zhang, J. Z. 2003. Overexpression analysis of plant transcription factors. Curr. Opin. Plant Biol. 6:430-440.

Zhu, C., Wu, J., and He, C. 2010. Induction of chromosomal inversion by integration of T-DNA in the rice genome. J. Genet. Genomics 37:189-196.

Zhu, Y., Nam, J, Humara, J. M., Mysore, K. S., Lee, L. Y., Cao, H., Valentine, L., Li, J., Kaiser, A. D., Kopecky, A. L., Hwang, H. H., Bhattacharjee, S., Rao, P. K., Tzfira, T., Rajagopal, J., Yi, H., Veena, Yadav, B. S., Crane, Y. M., Lin, K., Larcher, Y., Gelvin, M. J., Knue, M., Ramos, C., Zhao, X., Davis, S. J., Kim, S. I., Ranjith-Kumar, C. T., Choi, Y. J., Hallan, V. K., Chattopadhyay, S., Sui, X., Ziemienowicz, A., Matthysse, A. G., Citovsky, V., Hohn, B., and Gelvin, S. B. 2003. Identification of Arabidopsis rat mutants. Plant Physiol. 132:494-505.

Ziemienowicz, A., Merkle, T., Schoumacher, F., Hohn, B., and Rossi, L. 2001. Import of Agrobacterium T-DNA into plant nuclei: Two distinct functions of VirD2 and VirE2 proteins. Plant Cell 13:369-383.

Ziemienowicz, A., Shim, Y.-S., Matsuoka, A., Eudes, F., and Kovalchuk, I. 2012. A novel method of transgene delivery into triticale plants using the Agrobacterium transferred DNA-derived nano complex. Plant Physiol. 158:1503-1513.

Zipfel, C., Kunze, G., Chinchilla, D., Caniard, A., Jones, J. D., Boller, T., and Felix, G. 2006. Perception of the bacterial PAMP EF-Tu by the receptor EFR restricts Agrobacterium-mediated transformation. Cell 125: 749-760. 